\title{
Irregularidades invalidantes y nulidad de la elección según la experiencia de la jurisdicción constitucional española*
}

\author{
Invalidating Irregularities in an Electoral Process and \\ its Nullity According to the Experience of the Spanish \\ Constitutional Court
}

\section{Javier García Roca**}

Sumario:

I. Introducción

II. El sufragio pasivo como derecho fundamental y el alcance de su tutela jurisdiccional. ¿Existe un contenido esencial ex Constitutione?

III. Referencia comparada a las irregularidades electorales por la directa violación de principios constitucionales en México

IV. El cumplimiento escrupuloso de las reglas de elección: legalidad e igualdad electorales. Los criterios cuantitativo y cualitativo para determinar las irregularidades invalidantes

V. Los graves sucesos de las elecciones generales de 1989. La construcción de la nulidad parcial de la elección

VI. La oportuna reforma de la LOREG en 1991: la creación del amparo de proclamación de electos, el reforzamiento del papel de la Junta Electoral Central, y la distinta instancia jurisdiccional

VII. La integración de la legalidad electoral secundum Constitutionem. La ficción de imponer al órgano judicial el deber de integrar la ley conforme a la Constitución en vez de declarar la inconstitucionalidad

* El texto recoge la ponencia presentada al III Seminario Internacional del Observatorio Judicial Electoral del Tribunal Electoral del Poder Judicial de la Federación de México, el 6 de octubre de 2010, y actualiza mi libro Cargos públicos representativos. Un estudio del artículo 23.2 de la Constitución, Aranzadi, 1999, especialmente el capítulo IV "Un supuesto derecho fundamental de configuración legal o, mejor, con los requisitos que señalen las leyes”, y el capítulo VI "La igualdad en el acceso: el discutible alcance del artículo 23.2 en la regularidad de los procedimientos electorales", al que me remito in extenso. Pese a que este libro tiene ya una década, las bases doctrinales y jurisprudenciales en las que fundé mi construcción no han recibido modificaciones sustanciales y creo conserva su capacidad explicativa. Es más, detecto en la jurisprudencia posterior una consolidación de las tendencias entonces reseñadas. Para corroborar este aserto, el posterior trabajo Juan Carlos Duque, Elecciones políticas y Tribunal Constitucional. Jurisprudencia constitucional 1908-2005, Cizur Menor, Aranzadi Thomson, 2009.

** Catedrático de Derecho Constitucional, y director del Instituto de Derecho Parlamentario en la Universidad Complutense de Madrid, España.

Recibido: 3 de abril de 2013

Aceptado: 11 de octubre de 2013

D. R. @ 2014. Universidad Nacional Autónoma de México-Instituto de Investigaciones Jurídicas.

Revista Mexicana de Derecho Electoral, núm. 5, enero-junio de 2014, pp. 3-57,

México, D. F. 
Esta revista forma parte del acervo de la Biblioteca Jurídica Virtual del Instituto de Investigaciones Jurídicas de la UNAM

VIII. La relación causal entre irregularidades invalidantes y fallo anulatorio. Irregularidades consideradas en su conjunto

IX. Los errores irrelevantes en el cómputo tienen distintas consecuencias que el fraude electoral. Principio de conservación de los actos. Electores y votantes

$X$. El rechazo de interpretaciones formalistas enervantes del sufragio pasivo y de la votación mayoritaria de un candidato. Declaraciones de nulidad retrotrayendo a momentos posteriores al de la votación

$\mathrm{XI}$. Votos nulos y principio de inalterabilidad de las listas

XII. La posibilidad de la revisión directa del escrutinio o la necesidad de retrotraer al órgano judicial

XIII. Epílogo: el Tribunal Constitucional como garantía electoral y el solapamiento de las jurisdicciones electoral y constitucional

\section{Resumen:}

En el actual escenario del debate sobre la nulidad electoral por la violación de principios constitucionales, el artículo subraya la importancia del principio de legalidad electoral. Pero se pregunta qué tipo de irregularidades deben determinar la invalidez de la elección y cuáles deben ser las medidas de reparación. Aunque el modelo mexicano y el español son distintos, sobre todo por el importante papel arbitral de la Junta Electoral Central durante las campañas electorales, el fenómeno jurídico es el mismo y cabe una comparación. Se da noticia sistemática de la larga experiencia española en la revisión sucesiva de las irregularidades electorales. Se advierte del manejo por la jurisprudencia de un criterio cuantitativo - más numeroso-, cuando la irregularidad es determinante del resultado, junto a otro cualitativo que atiende al tipo de vicio y a su entidad. Y se razona sobre la necesidad de la interpretación - y la integración - de la legalidad electoral secundum Constitutionem.

\section{Abstract:}

In the current scenario of controversy about the election annulment due to the breach of constitutional principles, this article underlines the importance of the principle of electoral legality. The author asks himself about the kind of irregularities that should determine the cancellatin of the election and which type of measures should be taken in that case. In spite of the clear differences between Mexican and Spanish models - because of the role of the latter "Junta Electoral Central" during electoral campaigns-, the legal phenomenon is basically the same, and hence, a comparison is possible. The paper provides systematic information of the long Spanish experience on judicial review of electoral irregularities and conflicts. Here, we can find how constitutional jurisprudence has used two criteria at the same time: First, a quantitative approach (which is incumbent when the irregularity has actually changed the electoral outcome; which is a more common interpretation); and second, a new criteria related to the type of the irregularity. Finally, some arguments about the need on constitutionally congruent interpretation of electoral laws is presented.

Palabras clave: elecciones, irregularidades, nulidades, invalidez, justicia electoral.

Descriptors: Elections, irregularities, nullity, invalidity, electoral justice. 


\section{Introducción}

Este artículo tiene como tema la nulidad de la elección en el caso español, si bien se refiere antes a la declaración de nulidad de las elecciones por violación de principios constitucionales. Este planteamiento debe ser matizado, pues - como veremos- existe un fuerte principio de legalidad electoral y las causas de nulidad deben normalmente ser tasadas antes que implícitas, si bien pueden existir excepciones a la regla. Por otro lado, debe aclararse si hablamos de un control previo o sucesivo a la votación $v$. gr. de las campañas electorales, y resolver quiénes serían los sujetos con competencia para la declaración de nulidad.

Conviene precisar que España y México son, a estos efectos, dos términos de comparación poco homogéneos. Los conflictos electorales pueden ser semejantes, pues su finalidad es preservar la regularidad de las elecciones, pero los cauces procesales, las soluciones y posiciones jurisprudenciales puede que no sean iguales. El sistema español de justicia electoral está muy judicializado, si bien antes dos jurisdicciones diferentes que concurren en materia de garantías electorales. Primero, la contencioso electoral mediante instancias dentro de la jurisdicción contencioso administrativa que revisan los actos de esa especial administración que son las Juntas Electorales, y, luego, la constitucional con el amparo de derechos fundamentales ante el Tribunal Constitucional, pese a las serias limitaciones que posee la jurisdicción constitucional para poder revisar hechos. Sobre todo, este doble control represivo, jurisdiccional y sucesivo se complementa con otro control preventivo y arbitral que realiza la Junta Electoral Central entre otros extremos sobre el objeto y límites de las campañas electorales; un control arbitral y preventivo que falta en México y cuya ausencia incrementa en exceso el objeto del control jurisdiccional.

Juega, en efecto, un papel decisivo la Junta Electoral Central que es una extraña administración de garantía, muy tradicional entre nosotros, no prevista en la Constitución, y que depende orgánicamente, pero no funcionalmente, de las Cortes Generales. Está dotada de independencia en sus decisiones, pero no forma parte del Poder Judicial, pese a estar integrada en su mayor parte por magistrados del Tribunal Supremo. Un órgano de naturaleza compleja - si no contradictoria - pero muy eficaz, que tiene algo de poder legislativo, de judicial y de adminis- 
Esta revista forma parte del acervo de la Biblioteca Jurídica Virtual del Instituto de Investigaciones Jurídicas de la UNAM

tración independiente y de ninguno de ellos a la vez. ${ }^{1} \mathrm{Y}$, sin embargo, funciona...

El modelo electoral español no es pues el francés. Pues el artículo 70.2 de la Constitución Española (CE) atribuye al control judicial la validez de las actas de los miembros de ambas Cámaras en los términos que establezca la ley electoral. Los padres constituyentes no concedieron deliberadamente una competencia de revisión electoral al Tribunal Constitucional en el Título IX de la ley fundamental ni tampoco el legislador en su ley orgánica. Sin embargo, el reconocimiento del derecho de sufragio, en sus dos modalidades activo y pasivo, como derecho fundamental (artículo $23 \mathrm{CE}$ ), unido a la existencia de un recurso de amparo de derechos fundamentales, y la incidencia de dos cauces de amparo electoral que regula la ley electoral han ido haciendo cada vez más al Tribunal Constitucional un órgano de garantía electoral en una suerte de mutación constitucional. La introducción en 1991 de un recurso de proclamación de electos, junto al originario y sumario recurso de amparo de candidaturas, ha contribuido a reforzar esta situación. Si bien esta extensión de sus funciones posee límites y no debería erigirse siempre al Tribunal Constitucional en el intérprete de la legalidad electoral ordinaria, no obstante, puede controlar en abstracto la constitucionalidad de las leyes electorales y actuar como juez de concretas aplicaciones en el amparo electoral. Esos son los dos polos en tensión. La reforma de $2007^{2}$ para objetivar el amparo constitucional y permitir al Tribunal seleccionar lo importante - una especie de certiorari ibérico- no debería afectar mucho a los amparos

1 Sigo a Pablo Santolaya, catedrático y vocal de la junta electoral central, en "El modelo español de administración electoral”, en Delgado, Luis y Biglino, Paloma (coords.), La resolución de los conflictos electorales: un análisis comparado, Madrid, CEPC, 2010, pp. 21-46; también "Juntas electorales y separación de poderes", en Pauner, Cristina y Tomás, Beatriz (coords.), Las Administraciones independientes, 2009, pp. 227 y ss. También de Pablo Santolaya es una referencia clásica en España, con carácter general, Manual de procedimiento electoral, Madrid, Ministerio del Interior, 1991, que ha tenido sucesivas ediciones posteriores, y ha sido sometido a una reciente actualización y revisión muy completa auspiciada por el Instituto de Derecho Parlamentario de la Complutense: Procedimiento y garantías electorales, Madrid, Civitas Thomson Aranzadi, 2013.

2 Sobre la incidencia de la reforma del artículo 50 LOTC sobre la admisión del amparo producida por la Ley Orgánica 6/2007, de 24 de mayo, puede leerse Juan Carlos Duque y Juan Luis Requejo, "El recurso de amparo electoral sobre proclamación de candidaturas. Balance y perspectivas de la jurisprudencia constitucional”, en Biglino, Paloma (coord.), Proclamación de candidatos y garantías electorales: propuestas de reforma, Madrid, CEPC, 2008, pp. 37-108. 
Esta revista forma parte del acervo de la Biblioteca Jurídica Virtual del Instituto de Investigaciones Jurídicas de la UNAM

electorales, que es de esperar van a ser normalmente admitidos por su especial trascendencia constitucional según ha reconocido ya una sentencia constitucional (STC 155/2009, de 25 de junio) que fija unos criterios generales sobre la admisión. ${ }^{3}$

Sin embargo, adviértase que el Tribunal Constitucional no garantiza todas las fases del procedimiento electoral. Suelen llegarle recursos sobre proclamación de candidatos y de electos, un mínimo imprescindible. Pero no recursos contra el censo ni normalmente reclamaciones sobre la campaña electoral (publicidad, reparto de espacios, debates...), que por razones sustantivas, dada su naturaleza más arbitral que jurisdiccional en virtud de la indeterminación del parámetro de control, y de tiempo son imposibles de enjuiciar de forma preventiva por el Tribunal Constitucional. ${ }^{4}$

Como modelo alternativo está el Consejo Constitucional francés ${ }^{5}$ - en cuya exposición no me detendré- y al que la Constitución otorga el control de la regularidad de las elecciones, del referéndum y de la elección del presidente de la República. Pero recuérdese que no era inicialmente un verdadero modelo de jurisdicción constitucional, lo que explicaba que el Consejo no actuara como juez de constitucionalidad de las normas sino como juez electoral.

Frente a este sistema español de garantías electorales, bastante difuso, el mexicano es un ejemplo de modelo más concentrado o centralizado. ${ }^{6}$ Desde la reforma constitucional de 1996 y con la posterior

3 STC 155/2009, de 25 de junio, que interpreta la abierta cláusula "especial trascendencia constitucional” del artículo 50.1.b] de la Ley Orgánica del Tribunal Constitucional como requisito de admisión del amparo. Véase un comentario en Francisco Pérez De Los Cobos, actual Presidente del TC, "El requisito de la especial trascendencia constitucional para la admisión del recurso de amparo", pendiente de una eminente edición en una obra colectiva coordinada por Jaime Rodríguez Arana en la fundación SINTAGMA.

${ }_{4}$ Duque, Juan Carlos y Requejo, Juan Luis, op. cit., p. 85. Véase Gálvez, Luis A., Las campañas institucionales, Cizur Menor, Thomson Reuters Aranzadi, 2010, donde se recogen las instrucciones de la Junta Electoral Central sobre estas campañas, las decisiones del Tribual Supremo y de los Tribunales Superiores de Justicia, y alguna sentencia del Tribunal Constitucional en la que los actores invocan su tutela judicial efectiva u otros derechos. Debe verse Sánchez, Óscar, La igualdad de oportunidades en las competiciones electorales, Madrid, CEPC, 2007.

5 Véase, entre otros posteriores, Pardo, Javier, El Consejo Constitucional francés, Madrid, CEPC, 1990, capítulo III "El control de las elecciones nacionales y del referéndum".

${ }^{6}$ Véase Salvador Nava al que sintetizo: "Los conflictos electorales en la práctica: la experiencia en México", en La resolución de los conflictos electorales: un análisis comparado, cit., p. 249. 
Esta revista forma parte del acervo de la Biblioteca Jurídica Virtual del Instituto de Investigaciones Jurídicas de la UNAM

reforma de 2007-2008, el sistema está integrado por: a) la Suprema Corte de Justicia de la Nación encargada del control abstracto de constitucionalidad de la ley a través de la acción de inconstitucionalidad; b) y, sobre todo, el Tribunal Electoral Federal, conformado por una Sala superior y cinco salas regionales, y con competencia de control concreto de constitucionalidad de la ley y del control de legalidad de resoluciones y actos de las autoridades electorales tanto administrativas como jurisdiccionales, así como del control de los partidos políticos; c) treinta y dos tribunales electorales locales en cada entidad federativa con competencias sobre el control de legalidad local, y $d$ ) mecanismos de control administrativo y de organización de las elecciones de la competencia del Instituto Federal Electoral. El poder del Tribunal Electoral Federal como máxima autoridad jurisdiccional electoral y a la vez tribunal de jurisdicción electoral es pues muy grande.

En cambio, en las garantías del procedimiento electoral español concurren varios órganos jurisdiccionales de revisión con facultades de distinto alcance. Así las Juntas Electorales tienen sus facultades revisoras limitadas, lógicamente por la rapidez de su intervención. La Junta Electoral Central juega un papel esencial de intérprete mediante sus acuerdos e instrucciones donde se unifican criterios para una pluralidad de destinatarios. Y ante los tribunales contenciosos puede desplegarse plenamente la actividad revisora y la prueba de los hechos. Por último, el Tribunal Constitucional debería limitarse a garantizar en amparo el derecho de sufragio, interpretando sus contenidos, y a controlar la constitucionalidad de la ley. Al cabo lo importante es que el sistema de garantías electorales en su conjunto produzca un resultado armónico.

En abstracto, el problema esencial creo reside en diferenciar adecuadamente entre un control preventivo y arbitral, y muy excepcionalmente en alguna ocasión jurisdiccional, sobre todo acerca de las compañas electorales, y otro represivo o sucesivo de carácter judicializado donde la declaración de nulidad debería ser por definición excepcional, de funcionar bien el primero, por razones lógicas de economía, de conservación de los actos y de evitación del daño que provoca toda nulidad cuando el procedimiento electoral ya ha concluido. ${ }^{7}$

Cfr. con carácter más general, Beladíez, Margarita, Validez y eficacia de los actos administrativos, Madrid, Marcial Pons, 1994, y Cano, Tomás, La invalidez sobrevenida de los actos administrativos, Madrid, Thomson-Civitas, 2004, y respecto de la revocación 


\section{El sufragio pasivo como derecho fundamental y el alcance de su tutela jurisdiccional. ¿Existe un contenido esencial ex Constitutione?}

Si nos preguntamos acerca de cuál pueda ser el contenido ex Constitutione del sufragio pasivo o derecho de acceso en condiciones de igualdad a los cargos públicos con los requisitos que señalen las leyes (artículo 23.2 CE), ${ }^{8}$ y dejamos, por ahora, a un lado la jurisprudencia constitucional española -y la del Tribunal Europeo de Derechos Humanos o la de la Corte Interamericana-, e intentamos descontaminarnos de ella, pueden hacerse las siguientes consideraciones doctrinales a la búsqueda de una carta de navegación en un océano de resoluciones judiciales. Me preocupa precisar hasta dónde puede llegar el control de constitucionalidad de los derechos fundamentales respecto de la amplia libertad de configuración normativa del legislador electoral tanto como evidenciar que no todo el sufragio pasivo es de configuración legal.

Sigo un criterio habitual en la interpretación constitucional el cual es la conexión lógica de sentido entre un precepto y el resto de las normas constitucionales, es decir, un principio de concordancia o exégesis sistemática que se deriva del principio de unidad. Mi exégesis se centra en la Constitución Española, pero la metodología puede trasladarse fácilmente a cualquier otra ley fundamental en este contexto de derecho comparado y, en concreto, a la mexicana que tiene disposiciones de bastante detalle. Más reducida o de mínimos podría ser - aunque no necesariamente- la protección internacional conforme a los convenios regionales sobre derechos fundamentales en Europa e Iberoamérica. ${ }^{9}$

de actos de la administración electoral a Fabio Pascua, El control de las elecciones, Cizur Menor, Civitas, 2009.

${ }^{8}$ Es patente que discrepo de mi buen colega Manuel Pulido, El acceso a los cargos y funciones públicas: un estudio del artículo 23.2 CE, Madrid, Civitas, 1992, pp. 66 y ss., cuando califica el derecho fundamental "de naturaleza no sustantiva" y afirma que la Constitución "no constitucionaliza un concepto de cargo público sino que tal exhaustividad.... debe buscarse en la normativa reguladora del cargo en cuestión”. Una tesis extremada.

9 Puede consultarse García Roca, Javier, “Del compromiso internacional de los Esta- 
Esta revista forma parte del acervo de la Biblioteca Jurídica Virtual del Instituto de Investigaciones Jurídicas de la UNAM

Es éste un método de indagación del contenido de un derecho fundamental, más sencillo que una búsqueda estimativa y apriorística, ya sea siguiendo su conformación histórica en el constitucionalismo o no. Así, al analizar el estatuto de los parlamentarios, creo haber demostrado la inclusión de algunas facultades de titularidad individual en el contenido del derecho fundamental siguiendo otro método: interrogarme acerca de aquellas facultades e intereses, con un carácter indefectible o sine qua non, que permiten identificar la figura del parlamentario en su condición de representante. ${ }^{10}$

\section{La regularidad de la elección (artículo 66.1 CE)}

Habida cuenta de que, en el apartado 1, del artículo 23, se constitucionaliza el derecho al sufragio activo de los ciudadanos, junto al sufragio pasivo en el apartado 2, puede colegirse de la interrelación de ambas modalidades de sufragio que estamos hablando de cargos públicos de representación política, es decir, de puestos designados a través de elección por los miembros de una comunidad política. Los ciudadanos participan básicamente en los asuntos públicos por medio de representantes, libremente elegidos en elecciones periódicas por sufragio universal. En consecuencia, la regularidad de la elección es un interés objetivo y general que incumbe al derecho fundamental a salvaguardar sin el cual no resultaría recognoscible. Porque, si los resultados electorales no reflejan la voluntad de los ciudadanos manifestada en sus sufragios, se falsearía la representación y es obvio que no existiría igualdad en el sufragio activo - no todo hombre valdría un voto-, y, si algunos candidatos recibieran favores o agravios de los poderes públicos, tampoco en el sufragio pasivo, pues no todos los candidatos serían iguales en la concurrencia y competencia electoral, en definitiva, en las condiciones de acceso.

El artículo $23 \mathrm{CE}$ debe ser leído, comprendiendo la estrecha urdimbre que forman ambas modalidades de sufragio, y relacionándolo con

dos de organizar elecciones libres al derecho de sufragio de los ciudadanos (art. 3 Protocolo 1)", en García Roca, Javier y Santolaya, Pablo (coord.), La Europa de los derechos: el Convenio Europeo de Derechos Humanos, 2a. ed. corregida y aumentada, Madrid, CEPC, 2009, pp. 897-929.

10 García Roca, Javier, Cargos públicos representativos..., cit., Capítulo VII "La garantía de la igualdad en el ejercicio del cargo: el estatuto de los parlamentarios, y, en general, de los cargos públicos representativos...". 
el artículo 66.1 CE en el cual se afirma que las Cortes Generales representan al pueblo español. Es evidente, que la relación lógica entre estos dos preceptos se complementa con la consagración constitucional del Estado democrático (artículo 1.1), de la soberanía popular (artículo 1.2 ), y de la periodicidad de la elección o caducidad del mandato representativo (artículos 38.4 y 69.6), preceptos que conforman unas elecciones democráticas. ${ }^{11}$

Claro está que decir que es contenido del derecho la regularidad de las elecciones es una afirmación que no da respuesta a la inmediatamente pregunta ulterior: ¿frente a qué tipo de irregularidades en el procedimiento electoral concede garantía el derecho fundamental? En otras palabras, decantar la relación expuesta no resuelve si la adecuación a derecho del procedimiento por el que la elección se realizó es, en bloque, contenido del derecho fundamental o, por el contrario, existe una legalidad y una regularidad electoral que puede ser diferenciada sin que devenga objeto del derecho fundamental.

\section{La constitucionalidad de los requisitos legales de acceso: capacidad electoral y causas de inelegibilidad (artículos 12, 68.5 y 70 CE)}

Es fácil advertir otros intereses que deben estar también tutelados por el derecho fundamental, como ocurre con la existencia de unos requisitos legales para el acceso que sean constitucionalmente admisibles. Unas causas de inelegibilidad que superen un juicio de constitucionalidad, porque vengan previstas en las leyes, satisfaciendo la garantía formal en la regulación del derecho que entraña la reserva de ley y el más amplio principio de legalidad electoral, y que, además, establezcan requisitos materiales para el acceso que quepa enjuiciar como constitucionales.

Cabe, $v . g r$., exigir a estas causas que no excluyan de la elección a personas concretas o colectivos singulares, y que vengan dotadas de las deseables dosis de abstracción y generalidad que de las leyes normalmente se predica; piénsese en los ejemplos de algunos sistemas

11 Esta misma conexión de sentido de preceptos constitucionales sobre elecciones democráticas se hace por el Tribunal Electoral del Poder Judicial de la Federación en la SUP-JRC-165/2008, del 22 de febrero, considerando 5o., en el caso de las elecciones locales en el Ayuntamiento de Acapulco de Juárez. 
autoritarios en los que se excluye del sufragio pasivo y se impide presentarse a las elecciones a concretos ciudadanos o a miembros de una familia o grupo minoritario, o se exige la afiliación al partido único como condición para la capacidad electoral.

Asimismo, esas causas de inelegibilidad no pueden estar fundadas en criterios que quepa considerar en sí mismos odiosos y discriminatorios, cuales pueden ser la pertenencia a una etnia, o la condición femenina, o quienes profesen determinada religión o ideología, etcétera. $\mathrm{O}$, simplemente, criterios desprovistos de una justificación objetiva, proporcionada y razonable respecto de una medida tan grave como es la exclusión del sufragio pasivo; hoy no tendrían justificación normas como las dictadas, en otro contexto histórico, en el artículo 4o., letras $i, j$ y e del preconstitucional Real Decreto-ley 20/1977, del 18 de marzo, sobre normas electorales que declaraban inelegibles a quienes desempañaran ciertos cargos sindicales.

Puede, por tanto, decirse que es también contenido ex Constitutione del derecho la regulación legal de unas causas de inelegibilidad y de capacidad electoral que superen un juicio de constitucionalidad por razones formales y materiales, siguiendo las pautas del principio de proporcionalidad.

La conexión de sentido expuesta nos lleva en este extremo a varios preceptos constitucionales: al artículo 70 de la Constitución, que fija un elenco mínimo e indisponible de causas de inelegibilidad, sin perjuicio de que el legislador pueda establecer otras, según se hace en los artículos 6o. y 202, entre otros, de la Ley Orgánica 5/1985, del 19 de junio, de Régimen Electoral General (LOREG); así como al artículo 68.5 CE que obliga a que sean electores y elegibles todos los españoles que estén en pleno uso de sus derechos políticos y, finalmente, el artículo 12 CE acerca de la mayoría de edad, es decir, que posean capacidad electoral.

\section{3. ¿La igualdad real de los candidatos ante el sistema y el procedimiento electorales (artículos 69.2 y 140 CE)?}

Una vez garantizadas unas elecciones regulares, una capacidad electoral y unas causas de inelegibilidad razonables, constitucionalmente adecuadas, requisitos mínimos para un acceso igualitario de las candidaturas, podríamos preguntarnos si conviene ir más allá y debería ser contenido esencial o no del derecho de acceso en igualdad a los 
Esta revista forma parte del acervo de la Biblioteca Jurídica Virtual del Instituto de Investigaciones Jurídicas de la UNAM

cargos públicos la igualdad real ante el sistema electoral. Se trataría de saber si la relación entre la calificación que la Constitución hace del sufragio como "igual" (artículos 69.2 y 140) y la concreta igualdad en el acceso de los candidatos (artículo 23.2), obliga a llegar a esta conclusión; en otras palabras, si a la máxima clásica "un hombre un voto", que refleja la igualdad formal o jurídica, conviene añadir otra igualdad real, de peso o valor del sufragio.

Si obtener un escaño en el Congreso de los Diputados en la provincia de Soria, una circunscripción pequeña en población, en las elecciones generales de 1989 requería 26506 electores, y, en cambio, acceder al mismo puesto en Barcelona, otra circunscripción muy grande, exigía 113060 electores, es indudable que existe un tipo de desigualdad en la ley, en las reglas del sistema electoral, puesto que, de hecho, se exige a un candidato obtener muchos más votos que a otro para poder acceder a un mismo puesto y en aplicación de las mismas normas electorales.

Pero, podría también razonarse que uno y otro candidato, singularizados como término de comparación, no concurren en una misma circunscripción, ni, en realidad, ante un mismo electorado por lo que ambos supuestos de hecho albergan algunas diferencias. Mas ¿dónde quedaría entonces el dogma de la representación nacional conexo con la interdicción constitucional de mandato imperativo? Probablemente, sería más adecuado razonar que un sistema electoral puede tener en cuenta otros bienes constitucionales además de la estricta representatividad y la proporcionalidad, como son la gobernabilidad del país, o la voluntad de simplificar la complejidad de las sociedades para favorecer la gobernación (un clásico y peligroso argumento mayoritario), o la búsqueda del típico equilibrio federal entre pequeños y grandes territorios (lo que es una constante de cierta tradición y origen en el primer constitucionalismo desde el caso del Senado de los Estados Unidos y la equal footing clause), etcétera. O recordar que difícilmente un sistema electoral puede garantizar una igualdad estricta, entendida como pura proporcionalidad matemática - sin desviaciones- entre votos y escaños. O poner de manifiesto que las diferencias en el valor del sufragio derivan, de modo casi inexcusable, de la propia Constitución que, en el contexto de la Cámara Alta, exige elegir cuatro senadores en cualquier provincia, independientemente de su población; una patente desigualdad que no puede entenderse inconstitucional, pues procede de la propia norma fundamental y no existen normas consti- 
tucionales inconstitucionales, dada la igualdad en jerarquía de todas las normas constitucionales.

Admitiendo como válida cualquiera de estas razones, habríamos aceptado una desigualdad sustancial de trato en las condiciones de acceso. De hecho, los tribunales ordinarios, constitucionales (hay una curiosa excepción del alemán en las primeras elecciones tras la unificación) y supranacionales con funciones de garantías electorales no suelen revisar las desigualdades en el peso del voto creadas por las opciones del legislador al regular el sistema electoral, salvo las desproporcionadas y excluyentes barreras legales. Pues suele reconocérsele a la ley electoral una amplia libertad de configuración normativa y decisión política normalmente no susceptible de control de constitucionalidad.

\section{La constitucionalidad de las causas de cese (artículos 68.4 y $69.6 \mathrm{CE}$ )}

Alcanzado el acceso a un escaño en las Cortes Generales, o en un Parlamento autonómico, o en un Municipio, o Diputación Provincial, cabría pensar que, si una voluntad extraña a la relación de representación, configurada por ambas modalidades de sufragio, pudiera cesar instantáneamente al elegido y quebrar el mandato representativo, de nada habría servido la elección y no podría hablarse, en puridad, de cargo público representativo. Las causas de cese de los elegidos deben venir, por tanto, amparadas por el contenido del derecho, han de resultar precisadas en las leyes, conforme a un principio de legalidad electoral -y de tipicidad-, y estar debidamente justificadas. No en balde, la propia Constitución prescribe, como regla general, que el mandato de los diputados y senadores termina cuatro años después de su elección o el día de la disolución de la Cámara, sin agregar otras causas (artículos 68.4 y 69.6). Una protección que asimismo está dispensando el Tribunal Europeo de Derechos Humanos actualmente.

\section{La renuncia al cargo representativo (artículo 23.2 CE)}

En íntima ligazón, debería reconocerse la facultad que asiste a quien libremente accede a un cargo público de representación política pre- 
sentar su dimisión o renuncia, precisamente porque se encuentra ejerciendo un derecho subjetivo. La posibilidad de cesar a petición propia es una facultad sin la cual el derecho tendría una estructura normativa de deber u obligación constitucional, que no posee en el ordenamiento español, según se deduce del tenor literal del propio artículo 23.2, $\mathrm{CE}$, ni en cualquier democracia consolidada.

No son constitucionalmente admisibles condicionamientos que impongan el sometimiento de la renuncia de un cargo público representativo a su discrecional aceptación; la situación podría ser distinta para un cargo funcionarial o para un cargo no representativo. Otra cosa es que la dimisión pudiera venir en su caso limitada, si existe previsión legal al respecto, a su aceptación por la presidencia u otro órgano de dirección mediante el cumplimiento de ciertos requisitos temporales o formales. Pero nunca en virtud de un juicio de oportunidad política sobre la misma renuncia y dependiente de una voluntad ajena a las dos partes que mediante el sufragio configuran la relación de representación política. El cargo público representativo debe tener una fuerte responsabilidad política respecto de los electores, que lleva pareja la posibilidad de su renuncia, cuando se encuentre políticamente "incómodo" ante una actuación del órgano en que se integra y prefiera mantener el compromiso con sus electores.

\section{Los requisitos para la toma de posesión o adquisición de la condición de cargo público representativo (artículos 70.2, 23.1, 16 y 20.1, a) CE)}

Tampoco podría admitirse como adecuado a la naturaleza del derecho fundamental de sufragio pasivo que, una vez alcanzada la elección por el candidato, su toma de posesión como parlamentario, concejal o diputado provincial, o cualquier otro cargo representativo, exigiese el cumplimiento de requisitos, en sí mismos discriminatorios o lesivos de otros derechos fundamentales.

Repugnaría a la más elemental sensibilidad democrática que, para acceder al cargo de parlamentario, el electo, tras presentar su credencial o acta como electo, tuviera que jurar fidelidad a los principios inquebrantables de un régimen político o de un partido político o a un credo religioso. En todos estos casos, tales exigencias lesionarían sus libertades ideológica y de expresión (artículos 16 y 20.1, a], CE) amén del propio artículo 23.2 CE. 
Desde otra perspectiva, transgrediría asimismo el derecho de los electores a participar por medio de representantes (artículo 23.1 CE) que los electos no pudieran llegar a ejercer los cargos en virtud de obstáculos injustificables o desproporcionados, previstos en las leyes como requisitos para la toma de posesión o para adquirir la condición plena de diputado o representante. Pero qué duda cabe que $v . g r$. las declaraciones patrimoniales de los electos antes de su toma de posesión, para asegurarse de su probidad y la transparencia de su gestión son perfectamente legítimas si no se regulan de manera desproporcionada.

Es el momento de la elección el que debe resultar nuclear para la adquisición de la condición de un cargo al que se accede desempeñando un mandato representativo. La razonabilidad, proporcionalidad y regularidad de los requisitos para adquirir la condición de parlamentario, después de resultar elegido, parece que deberían también considerarse contenidos del derecho fundamental.

\section{El derecho a desempeñar las atribuciones del cargo} o "derechos funcionales", el ius in officium y la correlativa obligación de satisfacer los deberes propios del mismo (artículos 68.4, 69.5, 71.4 y 109 CE)

Es probable que un intérprete que no estuviera contaminado por la jurisprudencia constitucional española, y en consecuencia no pudiera influir en su argumentación, se detuviera en este punto. Porque no es obligado pensar que un derecho que la Constitución califica como de "acceso" deba extender su garantía a toda la relación jurídica posterior que surja tras el acceso o elección. De hecho, los comentaristas de los primeros años no se plantearon este problema y el Tribunal Europeo de Derechos Humanos no ha llegado a adentrarse en estas peligrosas aguas.

Pero tampoco es impensable que un intérprete atento a preservar el objeto de un derecho de participación política, llegase a la conclusión de que, si el cargo público no posee el derecho a conservar el puesto para el que fue elegido y a ejercer enteramente su mandato representativo, así como las facultades que las leyes le concedan para cumplir esta misión, la garantía sería ficticia. El desempeño de un cargo público parlamentario o municipal no puede contentarse con la 
Esta revista forma parte del acervo de la Biblioteca Jurídica Virtual del Instituto de Investigaciones Jurídicas de la UNAM

inicial elección sin devenir una garantía huera. La consideración de la representación como bien protegido por el derecho permite advertir que el mero acceso no garantiza la creación de una voluntad general del pueblo sino que es menester la atribución de una legitimidad y competencia al representante para poder decidir, y, en consecuencia, bien armada con las herramientas precisas.

Tampoco puede olvidarse que la Constitución busca que diputados y senadores puedan cumplir su mandato (artículos 68.4 y $69.5 \mathrm{CE}$ ), conservando su cargo público. Y que, entre otros derechos inherentes al cargo, concede a estos parlamentarios el derecho a percibir una asignación fijada por las respectivas Cámaras (artículo 11.4), así como permite al Pleno y a sus Comisiones recabar información del gobierno y de cualesquiera autoridades del Estado y de las comunidades autónomas (artículo 109).

Este conjunto de derechos funcionales del cargo conlleva otro de deberes. Un clásico como Costantino Mortati se preguntaba hace décadas por las condiciones para asumir el cargo de miembro del Parlamento y "para su conservación", y señalaba que el estatuto de miembro del Parlamento configura una posición jurídica, una fuente especial de derechos y deberes, que no puede ser rectamente interpretada si no se tiene en cuenta una pluralidad de relaciones en que los parlamentarios se encuentran: su derivación del cuerpo electoral y del mecanismo de la representación; la pertenencia a un partido a través del cual se manifiestan las opciones populares, y la cualidad de miembro de un órgano constitucional. Este doble ligamen con la sociedad y la persona jurídica estatal explica la complejidad de su posición constitucional. ${ }^{12}$

En el mismo sentido, la intuición de Georg Jellinek cuando en el siglo XIX afirmaba que los miembros del Parlamento pueden gozar de una "ampliación del status positivo" por ley; ${ }^{13}$ si bien creía que "al ser creada ex lege, puede ser ex lege abolida o transformada sin resarcimiento". En virtud de esa ampliación del status activae civitatis, el maestro reconocía que no sólo el diputado podía tener mayores derechos sino, al mismo tiempo, mayores deberes, al venir sometido a un poder de sujeción especial de la Cámara, el poder disciplinario;

12 Mortati, Costantino, Istituzioni di Diritto Pubblico, Padua, CEDAM, 1975, t. I, parte $4^{\text {a }}$, epígrafes "Condizioni per l'assunzione allo carico di membro dal Parlamento e per la sua conservazione”, pp. 475 y ss., y "Lo Status di membro dal Parlamento", pp. 486 y ss.

${ }_{13}$ Jellinek, Georg, Sistema dei Diritti Pubblici Subbiettivi, trad. de G. Viagliano, prólogo de V. Orlando, Milán, Socità editrice Libraria, 1912, pp. 183 y ss., "Il diritto degli eletti". 
กิ destacando que la obligación de intervenir en las sesiones o de dar $\dot{m}$ 을 $\quad$ el voto en muchas Constituciones o Reglamentos parlamentarios son formuladas como verdaderos deberes. Y mencionaba como deberes parlamentarios provistos de rigurosas sanciones, los casos de la Ley de Baviera sobre procedimiento del Landtag, del 29 de enero de 1872 (artículo 27), que obligaba a los miembros de la Cámara que no se acreditasen después de tres invitaciones a hacerlo o considerarse dimisionarios, y el de la Ley del 12 de mayo de 1873 de procedimiento del Reichstag austríaco (parágrafo 4), según el cual se consideraba dimisionario un diputado que no prestase juramento, o que tardase más de ocho días en presentarse en la Cámara, o que se ausentase de las sesiones sin licencia o justificar su ausencia, etcétera. ${ }^{14}$

Quizás este estatuto de derechos y deberes de los cargos públicos representativos protegidos por un derecho fundamental es la cuestión que más ha costado comprender a un sector minoritario de la doctrina científica española que podemos calificar de tradicional u organicista y que ha perdido claramente la batalla ante el Tribunal Constitucional.

\section{Recapitulación}

Existe un contenido esencial, constitucionalmente garantizado, del derecho fundamental al sufragio y a la participación política, y que no queda a la libre disposición del legislador. Un espacio que, cuando menos, abarca los siguientes contenidos: la regularidad de la elección, con los matices que convenga hacer, o igualdad en el acceso; las causas de inelegibilidad y la capacidad electoral; los motivos de cese; la dimisión o renuncia por voluntad propia; los requisitos para la toma de posesión o para adquirir la condición de cargo público representativo, y algunas de las atribuciones y derechos reconocidos a los cargos públicos representativos, como ocurre con los parlamentarios en las normas internas de las Cámaras o con los concejales en los municipios.

Si bien, tanto en el primero como en el último de estos requisitos, no será sencillo saber si el contenido del derecho protege la totalidad de su ámbito, ya que se entremezclan el contenido esencial o ex Constitutione del derecho fundamental, y lo que suele llamarse contenido adicional, ex lege o de configuración legal.

${ }_{14}$ Ibidem, p. 190. 
Las leyes electorales no podrían libremente disponer de este contenido esencial del derecho y, en consecuencia, debe ser susceptible de control, directamente por una jurisdicción constitucional con competencias electorales, o indirectamente, y a través de actos de aplicación por una jurisdicción ordinaria o contencioso electoral.

En México, a diferencia de España, ambas cosas se entremezclan en el Tribunal Electoral del Poder Judicial de la Federación (artículo 99 de la Constitución) que es tribunal de la jurisdicción constitucional y a la par máximo tribunal electoral, lo que refuerza su poder y facultades de actuación, entiendo que apenas desprovistas de otro límite que no es el control abstracto de la ley electoral. Una conclusión muy importante a reservar.

\section{Referencia comparada a las irregularidades electorales por la directa violación de principios constitucionales en México}

A la vista de los argumentos precedentes, efectuados de manera descontaminada, pues fueron pensados antes de 1999, se hace ahora una reflexión sobre la construcción en México de unas irregularidades invalidantes por la directa conculcación de las normas constitucionales tanto normas-reglas como, sobre todo, normas de principios. Se trataría - si no entiendo mal- de la erección de un principio de constitucionalidad electoral junto al de legalidad electoral, más habitual en derecho comparado. No existe tal categoría en el ordenamiento español, lo que evidentemente no quiere decir que las normas constitucionales no se apliquen directamente a las elecciones democráticas sin la necesaria mediación de la ley, salvo cuando sean simples mandatos al legislador electoral o normas de fines y requieran de la interposición del legislador; de manera que ello supone apartarse de la experiencia de nuestra jurisdicción constitucional que más adelante reseñaré y pensar por nosotros mismos. En definitiva, acaso no fuera menester la creación de ese principio específico y bastaría con el genérico principio de constitucionalidad que impone la sumisión de los poderes públicos y de los ciudadanos a la Constitución con mayor intensidad que al resto del ordenamiento jurídico (por ejemplo, artículo 9.1 CE). 
La tesis que se debate supone adherirse a la posibilidad de un contenido esencial - indisponible por el legislador- del derecho fundamental al sufragio, algo que justamente acabo de demostrar con los razonamientos generales que preceden a este epígrafe. El punto de partida no es pues a priori rechazable sino bastante compartible.

El Tribunal Electoral del Poder Judicial de la Federación se ha esforzado en construir esta doctrina especialmente en la SUP-JRC-165/2008, del 22 de febrero, ponencia de Carmen Alanís, caso elecciones locales en Acapulco de Juárez. Se arranca del problema que suscita la reforma del artículo 99, II, párrafo 2o., de la Constitución en 2007 el cual establece que: "Las Salas Superior y regionales del Tribunal sólo podrán declarar la nulidad de una elección por las causales que expresamente se establecen en las leyes". De manera que la reforma constitucional introduce un principio de tipicidad o taxatividad que es contenido habitual del principio de legalidad - lex stricta, previa, certa- también en materia electoral tanto en México, como en España. ${ }^{15}$ Se argumenta, no obstante, en la sentencia que debe garantizarse que las elecciones se ajusten no sólo a la legalidad sino también a la propia Constitución y, en consecuencia, caben irregularidades electorales por vulnerar principios constitucionales. Del carácter supremo de la ley fundamental (en una argumentación que recuerda al Marshall de Marbury versus Madison) se deduce que se admite una irregularidad que constituya una violación directa de las disposiciones constitucionales que permiten calificar una elección como democrática. Unas disposiciones que contienen verdaderas normas o mandatos vinculantes para el legislador - se dice- y susceptibles de tutela jurisdiccional. Por consiguiente, sin desempolvar la vieja "causal abstracta" debe caber una causa de invalidez electoral por la violación directa de la Constitución y un sistema de impugnaciones que las revise. Hasta aquí la motivación judicial creo que es impecable.

Más adelante se fijan varios requisitos que conforman esa causa de invalidez por una lesión constitucional:

- El relato de los hechos en la demanda.

- Su prueba.

15 La previsión legal de las causas de nulidad electoral, entendida como previsibilidad y certeza normativa más que como rango normativo, es también un criterio habitual de las decisiones del Tribunal Europeo de Derechos Humanos. 
- La afectación del proceso electoral.

- Que la infracción resulte, cualitativa o cuantitativamente, determinante del resultado electoral.

Estos elementos de la noción de constitucionalidad electoral me parecen razonables pues son los habituales del juicio de regularidad electoral en derecho comparado, pero con un matiz. Siempre y cuando la carga de la prueba u onus probandi en la demanda no sea desproporcionada para el actor y se limite a la exigencia de una diligente actividad probatoria dentro de sus posibilidades reales; pues puede haber supuestos de prueba diabólica o imposible y el Tribunal Electoral debería actuar en esos casos con cierta oficialidad en el impulso y con el antiformalismo suficiente para impedir indefensiones materiales; el límite de la congruencia con la pretensión debe no obstante preservarse. Pero no puede descartarse que ciertos indicios serios puedan llevar a inferir otros hechos con reglas lógicas, o a invertir la carga de la prueba como es ya habitual en la teoría de los derechos fundamentales.

El principal problema que se me ocurre deriva de si no estaremos rodeando la prohibición constitucional introducida en el artículo 99.2 incurriendo en un fraude o rodeo a la Constitución. Mas debe tenerse en cuenta que este tipo de normas prohibitivas demandan una interpretación constitucional estricta y no expansiva o ampliatoria. Podría entonces razonarse que la reforma constitucional veta las declaraciones de nulidad por causas legales implícitas o abstractas, imponiendo la presencia de causas tasadas y el juego de un principio de legalidad. Y que la reforma no se refiere ni impide — ni podría hacerlo como hipótesis de razonamiento- a la nulidad por motivos constitucionales, pues una norma constitucional no podría excluir la vigencia -la validez y eficacia - del resto de las normas constitucionales, si todas esas normas son iguales en rango y carecen de relaciones de jerarquía.

La complicación posible derivaría de los riesgos a la seguridad jurídica - tan importante en el procedimiento electoral- derivados de la aplicación directa y abusiva de la Constitución, sorteando a la ley electoral, sobre todo, cuando se trate de principios muy elásticos y flexibles, con mandatos muy indeterminados, y no de normas y reglas con contenidos más precisos. En suma, es menester asegurarse que no se vacíe el importantísimo principio de legalidad electoral respecto de la fijación de las causas que determinan la nulidad mediante un entendimiento tan elástico de la nulidad por principios constitucionales que 
Esta revista forma parte del acervo de la Biblioteca Jurídica Virtual del Instituto de Investigaciones Jurídicas de la UNAM

acabe por suponer una vuelta a la vieja causa abstracta o genérica. No olvidemos que el sufragio es un derecho fundamental de configuración legal. El propio Tribunal Europeo de Derechos Humanos ha insistido en que del principio de legalidad electoral se derivan las notas de previsibilidad y certeza de las causas de nulidad de la elección.

Del mismo modo, habría que asegurarse que estos vicios constitutivos de irregularidades electorales por violación de principios constitucionales no accedan per saltum al Tribunal Electoral del Poder Judicial de la Federación y que se respete la subsidiariedad y la invocación de estos motivos por los actores en las instancias previas tan pronto como hubo ocasión para ello. Así como asegurarse de la preclusividad o "definitividad" de las fases del procedimiento electoral, que es un rasgo consustancial del mismo.

Asimismo la afectación o determinación del resultado electoral cuando se enjuicien vicios cualitativos, y no en fase de cómputo o escrutinio tanto general por las Juntas como en las Mesas, sino de campaña electoral puede ser un juicio muy elástico e impreciso. Son dos tipos de juicio que tienen materialmente poco que ver.

Pero carezco de capacidad y experiencia para determinar el alcance real de esos riesgos según sus concretos conflictos en México. No obstante, no ocultaré - a la vista de los casos que se nos pide analicemos $-{ }^{16}$ que la judicialización de las campañas electorales es siempre muy arriesgada, me refiero a cuestiones como son la validez de mensajes publicitarios, la posibilidad de actos de precampaña o campaña anticipada, propaganda y campaña negativas o ilícitas — la llamada guerra sucia-, campañas institucionales y apoyo de los poderes públicos y de sus cargos y funcionarios a los candidatos, actuaciones de los

16 Cfr. SUP-JRC-165/2008, ponencia de la magistrada Carmen Alanís que en el texto se reseña; SUP-JRC-275 y 276/2007, ponencia del magistrado Manuel González, que contempla un interesante voto particular del magistrado Flavio Galván sobre la aplicación retroactiva de la reforma constitucional y los daños causados por la causal abstracta de nulidad; SUP-JRC-15/2008, ponencia de la magistrada Margarita Favela, referida a la separación entre la Iglesia y el Estado o principio de laicidad, muy detallista en la revisión de los hechos y de la prueba casi tanto como en una instancia; SUP-JRC 62/2009, ponencia del magistrado José Alejandro Luna, sobre transparencia informativa en Sonora, de nuevo con un voto particular del magistrado Flavio Galván quien aduce que rebasar el tope de gastos electorales no está previsto como causa de nulidad electoral y suscita diversos reparos de procedimiento y sobre la satisfacción del principio de subsidiariedad; SUP-JRC-604/2007, ponencia de la magistrada Carmen Alanís, sobre el uso de los símbolos religiosos por un candidato y en la propaganda electoral. 
Esta revista forma parte del acervo de la Biblioteca Jurídica Virtual del Instituto de Investigaciones Jurídicas de la UNAM

medios de comunicación y propaganda en Internet, actos de proselitismo por los ministros del culto y principio de laicidad o de separación entre la Iglesia y el Estado, tope de gastos electorales en campaña, reparto de los espacios electorales en radio y televisión, etcétera.

Pues probablemente es un objeto por su naturaleza más susceptible de un control arbitral y preventivo, a no ser que el parámetro de enjuiciamiento esté muy predeterminado en las leyes y el juicio devenga reglado, lo que no es sencillo. De hecho estos conflictos se controlan primero en España por la Junta Electoral Central, normalmente allí se agotan, y se revisan judicialmente en escasas ocasiones por el Tribunal Supremo y menos aún por el Tribunal Constitucional en tutela de derechos fundamentales, y desde luego no suelen determinar posteriormente la nulidad de la elección; cabría pensar pues en la posibilidad del fortalecimiento de los análogos institutos electorales. La revisión del conflicto sucesiva es siempre una solución más gravosa e indeseable que la preventiva. Por otra parte, es evidente que las intimidaciones a los votantes deben merecer una tutela penal y una adecuada garantía policial.

La mezcla del debilitamiento del principio de legalidad electoral que comporta la irregularidad por violación directa de las normas constitucionales y este tipo de objetos tan políticos puede ser problemática. Bien es verdad que las regulaciones constitucionales mexicanas sobre estos aspectos tienen bastante densidad y son, en cambio, inexistentes en España. Y, sobre todo, que cada sistema de garantías es fruto de su propia historia y de sus necesidades reales.

En todo caso, me parece que el Tribunal Electoral del Poder Judicial de la Federación cuando se encuentre ante una laguna legal, un supuesto de clara irregularidad electoral no prevista en la ley como causa de nulidad de la elección, podría hacer varias cosas. Primero, ampliar alguna de las causas legales de nulidad mediante una interpretación extensiva, si los hechos y los fines caben dentro de esa norma (interpretación extensiva). Segundo, en la medida en que participa de la jurisdicción constitucional, podría integrar la ley electoral con las normas constitucionales $y$, mediante esta integración, construir una norma que colme la laguna (integrar la ley con las normas constitucionales). Por último, podría incluso pensarse en la posibilidad de declarar una inconstitucionalidad por omisión y anular parcialmente la ley en la medida en que no contempla una causa de nulidad que cubra la nueva irregularidad invalidante que se ha detectado (inconsti- 
Esta revista forma parte del acervo de la Biblioteca Jurídica Virtual del Instituto de Investigaciones Jurídicas de la UNAM

tucionalidad por omisión). No en balde, el artículo 41, apartado VI, de la Constitución mexicana, igualmente reformado en 2007, establece que "para garantizar los principios de constitucionalidad y legalidad de los actos y resoluciones electorales, se establecerá un sistema de medios de impugnación en los términos que señale esta Constitución y la ley". Es incluso posible que el TEPJF pudiera, además de hacer una decisión de recomendación legislativa, redactar una sentencia aditiva de principios - como se llaman en la doctrina italiana-, fijándole al legislador algunos de los criterios que la nueva causa legal debe cumplir. Iniciándose así una muy necesaria colaboración entre legislador y Tribunal Electoral en el sistema de garantías electorales, uno detectando las irregularidades a través de la experiencia adquirida en los conflictos y otro regulando las sanciones.

IV. El cumplimiento escrupuloso de las reglas de elección: legalidad e igualdad electorales. Los criterios cuantitativo y cualitativo para determinar las irregularidades invalidantes

Reseñaré algunos de los pronunciamientos recaídos, sin otro afán que, al hilo de los mismos, atisbar ciertos criterios habituales de decisión acerca de irregularidades electorales y declaraciones de nulidad, siguiendo un método inductivo. ${ }^{17}$ Hasta donde alcanzo a saber no está todavía hecha por la doctrina científica una teoría general de la nulidad electoral ${ }^{18}$ como sanción a las irregularidades, labor sistemática y de construcción de categorías que convendría realizar en diálogo con la amplia jurisprudencia que a continuación trata de ordenarse.

${ }^{17}$ Es minuciosa la revisión de la jurisprudencia que efectuó Javier Pardo Falcón, "El contencioso electoral en la jurisdicción constitucional (Algunas cuestiones constitucionalmente relevantes en torno a la proclamación de candidatos electos)", Revista de las Cortes Generales, núm. 41, 1997, pp. 7 y ss. Más tarde y desde una perspectiva más procedimental, tanto Duque, Juan Carlos y Requejo, Juan Luis, "El recurso de amparo electoral sobre proclamación de candidaturas. Balance y perspectiva de la jurisprudencia constitucional", en Biglino, Paloma (coord.), Proclamación de candidatos y garantías electorales: propuestas de reforma, Madrid, CEPC, 2008, pp. 37-49; como Pascua, Fabio, op. cit.

18 Al igual que se ha hecho una teoría de la nulidad del acto administrativo, o de la invalidez de la ley por motivos de inconstitucionalidad. 
Esta revista forma parte del acervo de la Biblioteca Jurídica Virtual del Instituto de Investigaciones Jurídicas de la UNAM

Las sentencias constitucionales que expondré resuelven casos que reflejan experiencias bastante ricas, y han producido un adecuado diálogo entre el legislador y el intérprete supremo de la Constitución, ya que aquél ha ido ajustando y mejorando la ley constantemente en sus aspectos de procedimiento según se han ido detectando sus defectos o lagunas. ${ }^{19} \mathrm{Me}$ detendré en las primeras sentencias, que son las que construyen la doctrina, y no las últimas - como es un defecto habitual- aunque deban igualmente leerse para cerciorarse de los cambios. Por último, se advierte un intenso principio de legalidad electoral $-\mathrm{y}$ de tipicidad-, muy reforzado en el sufragio por ser un "derecho de configuración legal".

\section{Legalidad e igualdad electorales están asociadas en la exclusión de toda manipulación alteradora}

En una de sus primeras decisiones electorales, el Tribunal Constitucional (STC 21/1984, F. $4 .^{\circ}$ ), hablando del artículo 23.2 CE, aclaró que la igualdad y otros valores que se integran en la sustancia de un sistema democrático precisan: "Del cumplimiento escrupuloso de las reglas de elección de modo que se excluya toda manipulación alteradora de la voluntad del cuerpo electoral" (énfasis añadido).

Esta exigencia se puso en relación no sólo con los requisitos que señalen las leyes, como hubiera parecido más sencillo hacer, sino directamente con la igualdad en el acceso a la que el derecho fundamental responde y con otros valores propios de un sistema democrático. Legalidad e igualdad electorales se asocian directamente, una conclusión que merece la pena reservar. ${ }^{20}$ Hablamos de una igualdad integral

19 Es sumamente importante que las reglas del procedimiento electoral se aprueben con el compromiso de todas fuerzas políticas. La LOREG se ha modificado parcialmente desde 1985 en una decena de ocasiones. Todas las reformas se han aprobado con un elevado consenso parlamentario. El verano de 2010 la Comisión de Asuntos Constitucionales del Congreso de los Diputados ha aprobado el Informe de una subcomisión para una reforma de la ley en números extremos que en su mayor parte — salvo en transfuguismo y terrorismo- son lógicos ajustes técnicos de procedimiento; el sistema electoral no se toca.

${ }^{20}$ El Tribunal Europeo de Derechos Humanos analiza las irregularidades electorales, al amparo del derecho de sufragio lato sensu reconocido en el artículo 3 Protocolo 1 al Convenio Europeo, y suele detenerse, desde una aproximación pragmática si en la ley electoral no estaban suficientemente claros los concretos motivos por los cuales podía 
que engloba un juicio de regularidad. El fundamento se encuentra además en garantizar en un continuo el derecho al sufragio activo: en preservar la voluntad del cuerpo electoral. Hay efectivamente numerosas muestras de ese seguimiento escrupuloso de las reglas de elección. Veamos algunos casos.

\section{La declaración de nulidad puede suponer la convocatoria de una nueva "votación" o de un nueva "elección" según la entidad de la irregularidad.}

Una primera aproximación al artículo 113.2 LOREG, que fija los pronunciamientos posibles de la sentencia en el recurso contencioso electoral —en su redacción de 1985—, se produjo en la STC 169/1987, en la cual se declaró la nulidad de una elección y se sostuvo, que, del tenor literal de ese precepto, era forzoso reconocer que distingue entre "nueva convocatoria", en la circunscripción, y "nueva elección". La distinción abona la interpretación de que "nueva convocatoria" se refiere a la "convocatoria de un proceso electoral íntegro con inclusión de todas sus fases" (F. 4. ${ }^{\text {a) }}$. Habida cuenta de que ésta era la interpretación más favorable para el ejercicio del derecho fundamental, abrir la convocatoria tanto a los electores como a los elegibles, y, en definitiva, a la posibilidad de presentar nuevas candidaturas o de modificar las anteriores (idem).

El manejo de este criterio del favor libertatis, llevó a efectuar al Tribunal este pronunciamiento, muy condicionado porque la entidad recurrente reclamaba su derecho a sustituir unos candidatos en la nueva elección. Y si bien es cierto, se preserva el derecho de sufragio pasivo a través de la tutela de la facultad de un partido de presentar candidaturas, se adentra en la interpretación más adecuada del artículo 113.2, d) LOREG.

Mas no me parece que actuando de este modo el Tribunal se excediera de sus competencias constitucionales. De haberse repetido sólo el acto de la votación, se habría hecho imposible ponderar las lógicas modificaciones de las candidaturas por el transcurso del tiempo.

anularse los resultados, es la fase de la previsión legal de la interferencia en el juicio de proporcionalidad o principio de legalidad; véase, por ejemplo, el caso Kovach contra Austria de 7 de febrero de 2008. 
Pero, para llegar a ese resultado, el Tribunal Constitucional revocó la interpretación ofrecida a este precepto legal por la entonces Audiencia Territorial de La Coruña, que no era arbitraria ni se encontraba desprovista de razones.

En la actualidad, la reforma de la LOREG operada en 1991 modificó el tenor del artículo 113.2, d), añadiendo que la nulidad de la elección debe declararse en las Mesas que resulten afectadas por "irregularidades invalidantes”, y que la necesidad de efectuar nueva convocatoria podrá "limitarse al acto de la votación". Las experiencias de la jurisprudencia se suben a la ley. No obstante, el legislador no obliga a seguir necesariamente el criterio más favorable al derecho fundamental, una nueva elección en todas sus fases, sino que, ponderando otros bienes igualmente tutelables, permite una gama de soluciones según las circunstancias del caso concreto.

Los matices que en la posterior STC 25/1990, F. J. 8, in fine, se hicieron autorizan esta opción del legislador, pues se reconoció allí que la igualdad entre "nueva convocatoria" y "nuevo procedimiento electoral” podía romperse en el fallo de la Sentencia.

La actual solución del artículo 113 LOREG es técnicamente correcta. Desde otra perspectiva, evidencia los problemas que ocasiona el manejo del resbaladizo criterio del favor libertatis, como instrumento para una interpretación constitucional en temas no sustantivos como ocurre con el procedimiento electoral: favorecer la libertad de unos, sin mayores razones, puede perjudicar las libertades o competencias de otros. Las cosas son más complejas en una ponderación constitucional.

3. La noción de irregularidades invalidantes según los criterios cuantitativo y cualitativo: irregularidades determinantes del resultado electoral, y errores o arbitrariedades en la motivación judicial

En el caso de las elecciones locales al Ayuntamiento de Burgos, STC $71 / 1989$, la demanda alegaba que se cometieron errores e irregularidades formales en el procedimiento electoral. El Tribunal Constitucional reconoció que el principio de igualdad es un elemento esencial del derecho a acceder a los cargos públicos, "pero no agota su contenido", es también "un derecho de mediación legal” que encuentra su regula- 
ción fundamental en la LOREG, y, en tal sentido, "desde la perspectiva del derecho de sufragio pasivo, es obligado integrar en este derecho la exigencia de que las normas electorales sean cumplidas en cuanto constituyen garantía del correcto desarrollo de la elección" (F. J. 3º); de modo que se culmine con la proclamación de los candidatos que hayan sido preferidos por el cuerpo electoral.

Vuelve, pues, a ratificarse la pauta establecida en la STC 21/1984: el cumplimiento escrupuloso de las reglas de la elección. El pronunciamiento reconoce que la regularidad del procedimiento electoral forma parte del contenido del derecho fundamental tanto desde su naturaleza de derecho de configuración legal, y del consecuente carácter de la LOREG como mediación legal, como desde la misma igualdad en el acceso.

Esta afirmación parece requerir de algunos imprescindibles límites, por eso en la misma sentencia (F. J. 4) se reconoció que, al igual que cualquier transgresión de una ley no lo es de un derecho fundamental, no todas las infracciones de las normas de procedimiento electoral tienen relevancia constitucional para la tutela del derecho fundamental; únicamente es así cuando no se mantenga "la debida correlación entre la voluntad del cuerpo electoral y la proclamación de candidatos”. En pocas palabras: cuando la irregularidad sea determinante del resultado electoral.

Este criterio es el que el Tribunal Constitucional habitualmente maneja en los amparos electorales de proclamación de electos, y ofrece la indudable ventaja de la seguridad jurídica a la hora de su aplicación como regla de enjuiciamiento. Pero cabe dudar acerca de su naturaleza como verdadero criterio jurídico, al configurar una mera distinción de grado.

La pauta de la jurisprudencia española es, no obstante, semejante a otras en derecho comparado. Así se llama también en el derecho mexicano. Y tiene que ver con la "sinceridad de la elección" o de la "influencia determinante", que estimo es más amplia y que al parecer usa el Consejo Constitucional francés desde el caso Deval contra Durand, decisión núm. 58-55 del 5 de enero de 1959. Se revisó allí la elección de un diputado a la Asamblea Nacional en virtud de la colocación de carteles fuera de sus emplazamientos reglamentarios, lo que era una propaganda irregular al infringir las normas electorales. Pero el Consejo consideró que estos hechos no tuvieron una influencia determinante en el resultado de la votación, y también rechazó 
que tuviera el carácter de una manipulación electoral, el envío por un delegado departamental de unas cartas a los padres miembros de una asociación de enseñanza libre. La pauta consiste en examinar los hechos, para luego ponderar si hubo una influencia determinante sobre la sinceridad de la elección. Obsérvese que mientras el criterio de la irregularidad determinante del resultado en el entendimiento español se traduce en un sencillo cómputo numérico de votos y la posterior ponderación de su incidencia en el escrutinio, esta pauta de la sinceridad y de la influencia es tan elástica como la misma sinceridad como virtud humana y conlleva un enjuiciamiento no menos predecible.

Manejando lo que llamo un criterio cuantitativo - bien es verdad que algunas variaciones de cantidad producen un salto cualitativo-, el Tribunal Constitucional resolvió en esa STC 71/1989 que los "errores numéricos" y las "irregularidades formales" denunciadas no produjeron una alteración del resultado, puesto que en todo caso la candidatura recurrente no había alcanzado un porcentaje mínimo de un 5\%, que le permitirá superar la barrera legal exigida por el artículo 180 LOREG. El supuesto de hecho ilustra la sencillez del criterio español. La irregularidad no era constitutiva del resultado.

No obstante, cuanto precede no es tan claro que fuera la única motivación de rechazo ofrecida en la STC 71/1989, ya que en el mismo F.J. $4 .^{\circ}$, in fine, se dijo:

No existe circunstancia alguna que permita apreciar error notorio o arbitrariedad en la conclusión judicial de que las referidas irregularidades no han afectado el resultado final de la elección y de ello se deriva que no se ha producido lesión real y efectiva del derecho fundamental invocado por los demandantes.

El manejo de este segundo criterio, error o arbitrariedad en la resolución judicial, que la misma Sentencia alberga, puede que no sea siempre compatible con el primero.

Conviene pues diferenciar:

a) Un criterio cuantitativo encaminado a resolver si las irregularidades denunciadas condicionaron o no el resultado de la elección en el escrutinio general.

b) Y otro cualitativo dirigido a constatar si la interpretación o motivación judicial ofrecida a la previa denuncia de las irregularidades en el contencioso electoral era arbitraria, inexistente o funda- 
da en un error manifiesto o notorio. En abstracto, podría hacerse otro tanto directamente sobre el vicio de inconstitucionalidad electoral, pero el Tribunal Constitucional no suele hacerlo.

Existen ejemplos de sentencias constitucionales que usan uno u otro criterio. Esta segunda regla, que he calificado de "cualitativa", en cambio, sí me parece en abstracto un verdadero criterio jurídico, a diferencia del anterior. Pues atiende a la naturaleza o entidad de los vicios. Y evitaría erigir al Tribunal Constitucional en un órgano que resuelva una casación o unificación de doctrina electoral -improcedente por carecer de competencia-, o directamente en una Sala electoral de instancia. Salvo notorias excepciones, la justicia constitucional no ha sido diseñada para efectuar una valoración en torno a hechos según se desprende para el amparo constitucional en los artículos 41.3 y 44.1, b) de la Ley Orgánica 2/1979, del 3 de octubre, del Tribunal Constitucional (LOTC).

La cuestión, sin embargo, es verdad que se complica, porque los juicios de igualdad son uno de los ámbitos donde la conexión entre norma y hechos es, a menudo, tan estrecha que no puede disociarse. El juicio de igualdad electoral, inevitablemente, abre la justicia constitucional a juicios de "factibilidad" sobre hechos, y habría que admitir que la invocación de la igualdad del artículo 23.2, CE, obliga probablemente a hacer algunas excepciones en ocasiones a la regla general.

En todo caso, el criterio cuantitativo ha acabado por consolidarse en la jurisprudencia constitucional. Son muchas las sentencias que hacen un cómputo lógico o una ponderación estadística o un razonamiento hipotético de la relevancia de los votos controvertidos o desconocidos o inciertos para alterar el resultado de la elección ( $v . g r$. el cálculo de cocientes) conforme prescribe el artículo 113.3 LOREG ( $v$. gr. SSTC 26/1990, 166/1991, 169/1991, etcétera).

\section{Una justificación teórica: a priori no puede dilucidarse} a través del recurso de amparo cuál sea la interpretación correcta de la ley electoral ni cómo debió ser aplicada

En un recurso deducido frente a un Acuerdo de proclamación de electos a la Asamblea Regional de Cantabria en 1987, resuelto algo antes por la misma Sala Segunda del Tribunal Constitucional (STC 38/1989) se había, sin embargo, remarcado que: 
Esta revista forma parte del acervo de la Biblioteca Jurídica Virtual del Instituto de Investigaciones Jurídicas de la UNAM

No puede dilucidarse a través del recurso de amparo cuál sea la interpretación correcta de la ley electoral y cómo debió ser aplicada en el caso de autos, pues ésta es una cuestión que corresponde resolver a los órganos judiciales competentes de manera razonada y fundada en derecho (F. J. 2. ${ }^{\circ}$ ).

Un partido, el CDS, pretendía que se enjuiciara, invocando la igualdad, si había sido correcta la denegación de cómputo de unos votos en virtud de errores materiales en la transcripción de las actas en cada uno de los sobres. Se aducía que no se había seguido la misma pauta interpretativa por la Sala en los litigios resueltos en las diversas mesas electorales.

La decisión es un buen ejemplo de autocontención (self-restraint) del Tribunal Constitucional. ${ }^{21}$ Pero, obsérvese, que no dejan de existir ciertas dosis de contradicción entre la ratio decidendi de este pronunciamiento y la del epígrafe precedente. Parece que el intérprete supremo de la Constitución nada y guarda la ropa: de un lado, revisa irregularidades invalidantes por determinar el resultado electoral en el escrutinio, si es preciso, o corrige sentencias electorales que estima arbitrarias o erróneas, mojándose en el agua de la limpieza del procedimiento electoral, y, de otro, reconoce en línea de principios que no le incumbe, en amparo del derecho de sufragio, revisar la interpretación más adecuada de la ley electoral. Ambas sofisticadas afirmaciones están en una insoslayable tensión y puede que a veces en contradicción.

\section{La realidad: diversas excepciones en las que se interpreta la legalidad electoral o no según la irregularidad sea determinante del resultado}

Poniendo otra vez de manifiesto la contradicción que produce el manejo de uno u otro criterio, poco después, la STC 78/1989, el caso de las elecciones al Parlamento de Canarias en 1987, también de la

${ }^{21}$ Otra muestra de jurisprudencia respetuosa con los límites a la competencia del Tribunal Constitucional y basada en la autocontención es la STC 115/1995 donde se reconoció que no se vulneraba el derecho fundamental del artículo 23.2 CE al computar lo números enteros y sus decimales en el cálculo de cocientes conforme a la regla D’Hondt, puesto que esta era una interpretación razonable de la regla establecida en el artículo 163 LOREG; y pese a que la parte actora aportó algunas resoluciones de otras Sala de lo contencioso en los que la controversia legal se interpretaba de manera distinta, 
Esta revista forma parte del acervo de la Biblioteca Jurídica Virtual del Instituto de Investigaciones Jurídicas de la UNAM

Sala Segunda e igualmente en relación con el problema de los sobres electorales, se adentró en la interpretación que conviniera dar a los artículos 108 y siguientes. LOREG en su redacción inicial de 1985, sentando el criterio de que las Juntas Electorales no pueden, durante el periodo de reclamaciones que se abre tras el escrutinio, más que resolver las concretas reclamaciones que presenten los representantes y apoderados, sin que se les pueda exigir actuaciones de oficio, en situaciones con evidentes conflictos de intereses entre candidaturas enfrentadas (F. 4..$^{\mathrm{s}}$ ).

El CDS denunciaba en la demanda de amparo que hubo un error en el cómputo efectuado en el escrutinio, puesto que no llegaron a poder de la Junta Electoral los sobres primero y tercero de una Mesa, sin que aquélla requiriese del Juzgado de Primera Instancia el llamado segundo sobre. Todo lo cual el CDS propuso como medio de prueba en el contencioso electoral siéndole denegado.

El Tribunal Constitucional rechazó que la Junta Electoral debiera haber reclamado de oficio el segundo sobre tanto en el escrutinio como en el posterior periodo de reclamaciones. Si bien - afirmó- es indudable que "la finalidad legal de los segundos sobres no parece que deba limitarse a permanecer en los archivos de los Juzgados sin otra finalidad que su eventual aprovechamiento por futuros investigadores" (F. J. $3^{\circ}$ ). Su obvio destino es permitir subsanar "en su momento", el control judicial, las irregularidades acaecidas en la documentación electoral (ibidem). El amparo, pese a ello, se desestimó, porque la prueba fue considerada no pertinente por la Sala de lo Contencioso correspondiente.

A mi parecer, en esta Sentencia el Tribunal Constitucional interpretó directamente varios preceptos de la LOREG de manera acaso innecesaria - un obiter dicta-, ya que tal motivación no era precisa para desestimar el amparo. Hubiera bastado sencillamente con decir que reclamar el segundo sobre no era legalmente posible para la Junta Electoral y que en el contencioso electoral ya se motivó la falta de pertinencia de la prueba. Pero el Tribunal no se contuvo ahí e interpretó el verdadero sentido de los artículos 100 y siguientes, LOREG, sobre la intervención tasada de las Juntas Electorales.

Conviene traer a colación que el legislador, en la reforma de la LOREG operada en 1991, modificó varios preceptos legales y, de nuevo, no exactamente en el sentido expresado en dicha sentencia, antes bien al contrario. Recuérdese que, el hoy artículo 101.4, reza "los segundos 
Esta revista forma parte del acervo de la Biblioteca Jurídica Virtual del Instituto de Investigaciones Jurídicas de la UNAM

sobres quedarán archivados en el Juzgado de Primera Instancia o Paz correspondiente, pudiendo ser reclamados por las Juntas Electorales en las operaciones de escrutinio general, y por los Tribunales competentes en los procesos contencioso-electorales".

Justo en la sentencia posterior, la STC 79/1989, el caso de la Junta Electoral de Zona de Ponferrada, también en elecciones locales, el Tribunal volvió a situarse en una correcta línea restrictiva o de autocontención:

No todas y cada una de las secuencias del procedimiento son igualmente relevantes para el proceso constitucional. No nos corresponde, por tanto, entrar a fiscalizar, sin límites, el control realizado por los Jueces ordinarios sobre la pulcritud del procedimiento electoral y los efectos de los vicios en él acotados sobre el resultado proclamado por la Junta Electoral, de acuerdo con lo previsto en el art. 113.3 de la Ley Orgánica 5/1985. El control constitucional en amparo sobre la regularidad del procedimiento electoral - verificada ya una revisión del proceso electoral por los Tribunales ordinarios - debe ceñirse a la indagación relativa a si, dados los hechos apreciados por el órgano judicial, los vicios procedimentales así constatados pudieron afectar al resultado de la elección misma y, a través de éste, a la integridad del derecho fundamental aquí comprometido (artículo 23.2 CE) (F. J. 2. ${ }^{\circ}$.

La Sala Segunda razonó que la Sentencia dictada por la Audiencia Territorial de Valladolid había hecho una minuciosa revisión del escrutinio, argumentando que las irregularidades expuestas no podían conducir a anular total o parcialmente la elección por no ser determinantes del resultado (artículo 113.3, LOREG). Y no podía pretenderse en vía de amparo una reconstrucción fáctica, puesto que eso: "Sería transformar el recurso de amparo en una instancia de apelación más allá del ámbito propio del amparo constitucional" (F. J. $2^{\circ}$ ). Para preservar la tutela judicial efectiva, el Tribunal Constitucional declaró que si se denuncian en el contencioso electoral errores materiales en el recuento hecho por las Juntas Electorales que pueden afectar el reparto de concejales, la Sala de Justicia debe verificar ese pretendido error, impidiendo que se cause una indefensión (STC 93/1989).

Podríamos continuar poniendo ejemplos que ilustren este confuso camino o doble criterio para el enjuiciamiento constitucional, pero carecería de mayor interés para los fines argumentativos que se pretenden. 
Esta revista forma parte del acervo de la Biblioteca Jurídica Virtual del Instituto de Investigaciones Jurídicas de la UNAM

\section{Los graves sucesos de las elecciones generales de 1989. La construcción de la nulidad parcial de la elección}

En esta reseña de jurisprudencia sobre regularidad de las elecciones, llegamos a los importantes sucesos políticos acaecidos en las elecciones generales de 1989, que fueron apaciguados a través de la doctrina emanada en las SSTC 24, 25, 26 y 27/1990. Alguna similitud parece poseer el asunto con el de las elecciones presidenciales mexicanas de 2006 pero sólo en dos aspectos: la trascendencia política del asunto, y que el conflicto se producía en fase de escrutinio; mas el cúmulo de irregularidades advertidas eran muy diferentes en ambos casos. Por vez primera, en nuestra entonces aún adolescente democracia, se puso en tela de juicio por la oposición al gobierno del señor González -varias veces reelecto- la validez del procedimiento electoral, para traducir las preferencias del electorado en "cuotas de poder político". ${ }^{22}$ Pese a que, un lustro antes, la LOREG había sido aprobada de manera ampliamente consensuada. Un gravísimo problema, puesto que difícilmente puede sobrevivir una democracia representativa si se siembran dudas acerca de la limpieza y regularidad del procedimiento electoral y del sistema de garantías: ${ }^{23}$ si se golpea en el mismo corazón de la formación democrática de la voluntad estatal. Ese fue precisamente uno de los problemas centrales del constitucionalismo liberal en la España del siglo XIX: el falseamiento de las elecciones que no traducían la voluntad popular.

22 Así se expresa Santolaya, Pablo, "La crisis del procedimiento electoral”, en varios autores, Reflexiones sobre el régimen electoral (IV Jornadas de Derecho Parlamentario: la legislación electoral), Madrid, Congreso de los Diputados, 1997, quien hace evidente que mientras los rasgos de un "sistema electoral" pueden ser objeto de discusión política, las normas procedimentales en sus elementos básicos, si son seriamente discutidas, acaban por situar en crisis la misma capacidad del modelo para generar representación ante las dudas acerca de la limpieza de todo el modelo: un camino "degenerativo".

${ }^{23}$ En este mismo sentido se manifestó sensatamente Solé Tura, Jordi, "El Tribunal Constitucional y las elecciones", El Periódico, 18 de febrero de 1990, nada más darse a conocer esta sentencia: una cosa es discrepar de la decisión de un tribunal y otra bien distinta que se desacredite la legitimidad de todo un sistema político, envenenando la validez del sistema y procedimiento electorales. 
Esta revista forma parte del acervo de la Biblioteca Jurídica Virtual del Instituto de Investigaciones Jurídicas de la UNAM

Afortunadamente, en las elecciones generales siguientes, las de 1993, pese a ser de resultados aún más ajustados, y en posteriores consultas las críticas al procedimiento electoral -otra cosa es al sistema electoral - han disminuido sensiblemente y prácticamente han desaparecido las descalificaciones globales. El modelo puede ser imperfecto, como todo lo humano, y susceptible de mejoras periódicas mediante reformas parciales a la LOREG, pero asegura unas más que notables dosis de regularidad en el funcionamiento de la administración y el procedimiento electorales, y en la ulterior revisión judicial, en vía contenciosa, y ante la jurisdicción constitucional.

La decisión central de esas cuatro sentencias es la STC 24/1990, el caso de las elecciones en Murcia, cuya ponencia asumió el magistrado Tomás y Valiente, respetado presidente del Tribunal y años después alevosamente asesinado por el grupo terrorista ETA en su modesto despacho de universitario.

La Junta Electoral Provincial proclamó electos al Congreso a cuatro candidatos del PP, y al primero, respectivamente, del CDS y de IU. Un resultado al que se llegó después de que se decidiera no computar veintisiete mesas electorales: veinticinco por existir en cada una de ellas más votos o papeletas que votantes o electores, y otras dos por no estar en los sobres el acta de escrutinio. Contra este acuerdo, el PSOE promovió un contencioso electoral, pidiendo que se computaran todas esas mesas y que se rectificase la proclamación de electos, adjudicándole el quinto escaño, así como tres al PP, uno al CDS y ninguno a IU hasta un total de nueve.

El Tribunal Superior de Justicia de Murcia afirmó que no debieron computarse sólo esas mesas y que, en consecuencia, resultaba afectado el resultado electoral en relación con el último escaño controvertido entre IU y el PSOE y, aplicando literalmente el artículo 113, apartados 2, c) y 3, LOREG, en la redacción de 1985 anuló la elección en toda la circunscripción. En estos preceptos se decía que la sentencia, entre otros fallos posibles, habrá de pronunciar la nulidad de la elección y la necesidad de convocar otra nueva elección, salvo "cuando el vicio del procedimiento electoral no sea determinante del resultado de la elección".

Promovidos sendos recursos de amparo por el PSOE y el CDS, el Tribunal Constitucional otorgó el amparo, anuló la sentencia impugnada y restableció en su derecho fundamental a los ocho primeros candidatos, reconociendo la validez de la proclamación de electos 
Esta revista forma parte del acervo de la Biblioteca Jurídica Virtual del Instituto de Investigaciones Jurídicas de la UNAM

efectuada por la Junta Electoral. Y, respecto del controvertido noveno escaño, retrotrajo las actuaciones al momento anterior al de dictar sentencia, para que la Sala recabase los segundos sobres de las dos mesas discutidas y, una vez recibidos, si era posible con garantías suficientes de autenticidad, integrara los resultados de esas dos mesas con los de las otras mil ochenta y cinco y, caso contrario, declarase la nulidad parcial de la elección únicamente en dichas dos mesas, procediéndose a una nueva votación.

En pocas palabras, un lógico principio de conservación de los actos válidamente emanados, abocó al Tribunal Constitucional a defender, en vez de una lectura literal y rigorista de la ley electoral — como hizo el órgano judicial de procedencia-, otra finalista y favorable a la vigencia de los derechos fundamentales de sufragio activo y pasivo, que no produjera la nulidad absoluta de la elección en toda la circunscripción sino una nulidad parcial en sólo las dos mesas afectadas de irregularidades. La sentencia (F. J. 6º habla de una "interpretación integradora" del artículo 113 LOREG "conforme a la Constitución”. Pero debe admitirse que la nulidad parcial fue el fruto de una interpretación constitucional constructiva de normas y no estaba en la ley.

Ciertamente, un argumento de estricta proporcionalidad entre la sanción y la entidad de la irregularidad aconsejaba defender esta cabal posición: dos Mesas con irregularidades entre un total de casi un millar y un ciento en toda la circunscripción. Pero esta consideración lógica no permite eludir la presencia de un problema previo que suscita reparos a cualquier jurista acostumbrado por oficio a acatar las leyes: ¿tenía competencia el Tribunal Constitucional para adentrarse en la interpretación de ese extremo y crear un nuevo tipo de nulidad?

En este sentido, la sentencia contempla un voto particular (magistrado Rubio Llorente) escueto, pero sólido en su fundamentación, en el cual se dice que la sentencia impugnada no pudo lesionar derecho fundamental alguno por dictar uno de los fallos legalmente previstos en el artículo 113, LOREG, la nulidad de la elección, una vez determinado que el número de votos no computables podía alterar el resultado final, y concluye:

Me parece evidente que la actual regulación del contencioso electoral es manifiestamente inadecuada, pero no es tarea de este Tribunal corregirla y menos aún imponiendo una interpretación difícilmente compatible con la literalidad del precepto... 
Esta revista forma parte del acervo de la Biblioteca Jurídica Virtual del Instituto de Investigaciones Jurídicas de la UNAM

La tesis del voto particular engarza con cuanto se ha venido razonando en este epígrafe. ¿Justificaba la defensa del sufragio y su conexión con la regularidad del procedimiento electoral el que el Tribunal Constitucional hiciera una labor, más propia de un recurso de casación que de amparo de derechos, de interpretación de la legalidad electoral, buscando la solución técnicamente más correcta? O, por el contrario, actuando de este modo, ¿se estaba adentrando en la asunción de una competencia en materia electoral que, a diferencia de otros modelos hipotéticamente posibles -el Consejo Constitucional Francés-, la Constitución no le concede? ¿No estaba el Tribunal Constitucional ejerciendo una funzione di suplenza o una invasión del legislador? La incógnita no es fácil de despejar.

Una de las posiciones críticas más consistentes respecto de esta sentencia fue la defendida por Javier Pérez Royo. ${ }^{24} \mathrm{~A}$ su juicio, la interpretación ofrecida por el Tribunal Constitucional era acertada desde una óptica de justicia material, conforme al principio de proporcionalidad entre vicio y sanción, pero no desde una perspectiva formal. El Tribunal no podía adoptar la decisión que tomó y, al obrar así, actuó como una segunda instancia de los Tribunales de Justicia, administró justicia sin tener competencia para ello; puesto que una cosa es que el artículo 23 de la Constitución se viera "afectado" por una sentencia dictada en un contencioso electoral, y otra bien distinta es que la resolución judicial "vulnerase" derechos fundamentales. El Tribunal Constitucional - decía- no remedió la lesión de un derecho fundamental, antes bien revisó la interpretación de la ley hecha por un tribunal competente y de manera suficientemente motivada, fuese acertada o no.

Fue también crítico - más exacto es decir que dubitativo- Juan José Solozábal, ${ }^{25}$ quien, de un lado, manifestó su aplauso a la intervención restauradora del crédito democrático por parte del Tribunal Constitucional, y, de otro, evidenció sus escrúpulos sobre la cobertura normativa de tal actuación.

En cambio, se mostró favorable al criterio seguido por el Tribunal Miguel Satrústegui, ${ }^{26}$ quien destacó la inercia legislativa del artículo

24 Véase Pérez Royo, Javier, “Sobre la sentencia”, El País, 17 de febrero de 1990, p. 12.

${ }_{25}$ Cfr. Solozábal, Juan José, "Sobre la jurisprudencia constitucional en materia electoral”, Revista Española de Derecho Constitucional, núm. 30, 1990, pp. 146 y ss.

26 Véase Satrústegui, Miguel, "Las garantías del derecho electoral”, Revista de las Cortes Generales, núm. 20, 1990, pp. 91 y ss. Tiempo después, en 2009, Parra, Fabio, op. cit., epígrafe "La controversia en torno a la eventual naturaleza del Tribunal Constitucional como tribunal de garantías electorales”, pp. 219-229. 
Esta revista forma parte del acervo de la Biblioteca Jurídica Virtual del Instituto de Investigaciones Jurídicas de la UNAM

113.2, d, LOREG, respecto de la vieja Ley de Maura de 1907, bajo cuya vigencia la mayoría de las circunscripciones eran uninominales lo que explicaba la nulidad absoluta. Recordó además que la interpretación finalista, hecha por el Tribunal Constitucional, acerca de la nulidad parcial de la elección tenía precedentes de derecho comparado en la legislación electoral alemana (artículo 44) y austríaca (artículo 111). Y concluyó que, sin desdeñar posibles reformas legislativas más precisas sobre el carácter de la nulidad en materia electoral y el contenido posible del fallo anulatorio, estimaba que sería equivocado reducir la función del Tribunal Constitucional para reforzar, en cambio, la del Tribunal Supremo. Un planteamiento que creía carecía de suficiente fundamentación, tanto política como técnica, porque ni basta con invocar los peligros de politización del Tribunal Constitucional, ni la intervención del Tribunal Supremo resolvería nada. El recurso de amparo no depende de la ley electoral y no es previsible que su uso disminuyera por introducir un recurso contencioso ante el Tribunal Supremo, que únicamente retrasaría la solución de eventuales litigios. A la vez señalaba que era difícil resolver recursos contencioso-electorales con criterios de mera legalidad sin que estén en juego los derechos fundamentales afectados.

Hasta aquí la bien argumentada posición de Satrústegui. No obstante, es patente que tampoco se encuentra una respuesta al verdadero problema, que no es otro que la falta de competencia electoral del Tribunal Constitucional, según el modelo diseñado por la norma fundamental, de acuerdo con la voluntad de los padres constituyentes, y por su Ley Orgánica.

Como conclusiones principales, la situación conduce a una confusión o concurrencia de jurisdicciones, ${ }^{27}$ al dar por supuesta, sin necesidad de ulteriores justificaciones, una inescindible conexión entre legalidad electoral y tutela de derechos fundamentales de configuración legal casi una identidad. Esta es una conclusión no sé si inevitable, pero que - sostenía en 1999- requería de mayores argumentaciones desde la perspectiva del derecho fundamental y de la división de poderes. Mas la situación no ha cambiado en 2010.

27 De superposición de jurisdicciones, comentando estas sentencias de 1990, habla Biglino, Paloma, "La validez del procedimiento electoral en la jurisprudencia del Tribunal Constitucional”, Revista Española de Derecho Constitucional, núm. 29, 1990, pp. 291 y ss. Más matizado es Caamaño, Francisco, "Elecciones y Tribunal Constitucional ¿una intersección no deseada”, Revista de las Cortes Generales, núm. 41, 1997, si bien entiende como "inevitable" (p. 121) la función del Tribunal Constitucional como órgano de garantías electorales. 
Esta revista forma parte del acervo de la Biblioteca Jurídica Virtual del Instituto de Investigaciones Jurídicas de la UNAM

En segundo lugar, el Tribunal Constitucional asume la capacidad de integrar la ley electoral con la Constitución en ciertos casos, construyendo normas que colmen las lagunas.

\section{La oportuna reforma de la LOREG en 1991: la creación del amparo de proclamación de electos, el reforzamiento del papel de la Junta Electoral Central, y la distinta instancia jurisdiccional}

La reforma de la LOREG operada por la Ley Orgánica 8/1991, del 13 de marzo, mejoró sensiblemente las cosas tras la experiencia adquirida en estos casos. Acertadamente, se introdujo una doble instancia en el seno de la Administración Electoral, dando un papel primordial a la Junta Electoral Central ${ }^{28}$ a la hora de fijar y unificar criterios (artículo 108.3) y de manera extremadamente célebre. Permitiéndose después el acceso bien a los Tribunales Superiores de Justicia bien al Tribunal Supremo, según el tipo de elección. Y, por último, se previó una vía específica de amparo electoral contra proclamaciones de electos (artículo 114 de la LOREG), con plazos especialmente breves en su tramitación ante el Tribunal Constitucional, un cauce sumario y específico que antes no existía.

En lo que atañe a las elecciones generales a Cortes, según el artículo 122, LOREG, en el texto adoptado en 1991, el tribunal competente para la resolución de los recursos contencioso-electorales es el Tribunal Supremo, así como para las elecciones al Parlamento Europeo, dado el carácter único de la circunscripción nacional. Pero, en las elecciones autonómicas o locales, los tribunales competentes son las salas de lo Contencioso-Administrativo del Tribunal Superior de Justicia de cada

${ }_{28}$ Muy interesante es Arnaldo, Enrique, "La interpretación de la normativa electoral por la Junta Electoral Central (1977-1997)”, Revista de las Cortes Generales, núm. 41, 1997, pp. 169 y ss., quien sugiere — siguiendo a Pablo Santolaya- reforzar el proceso de institucionalización e incremento de las competencias de ese órgano; una reflexión plenamente compartible. Las propuestas de la Comisión de Asuntos Constitucionales de 2010 de reforma de la LOREG asimismo robustecen las competencias de la Junta Electoral Central para unificar criterios en muchas materias: motivos de excusas de los miembros de las Mesas, incumplimiento por los Ayuntamiento del deber de actualizar mensualmente y en plazo el censo, etcétera. 
Esta revista forma parte del acervo de la Biblioteca Jurídica Virtual del Instituto de Investigaciones Jurídicas de la UNAM

Comunidad Autónoma. Por consiguiente, la posibilidad de que diecisiete Tribunales Superiores interpreten de manera diversa la legalidad electoral no parece impensable. ${ }^{29} \mathrm{El}$ problema es más grave en las elecciones locales, pues la ley es la misma en las numerosas circunscripciones y son mayores los riesgos y, al tiempo, las exigencias derivadas de la necesidad de una interpretación uniforme.

Algo se ha avanzado, sin duda, respecto de la situación previa, con el acceso a la Junta Electoral Central para la solución de recursos contra las reclamaciones frente al acta de escrutinio que sean resueltas por las distintas Juntas Electorales. Una labor que permite una muy deseable unificación de doctrina por este órgano, técnicamente cualificado y que goza de autoridad, de la exégesis hecha por la Administración electoral.

Mucho se adelanta también atribuyendo únicamente al Tribunal Supremo la solución de recursos contencioso electorales en dos tipos de elecciones, las generales y al Parlamento Europeo: alcanzar una interpretación unitaria de la LOREG. Pues es obvio que es el órgano jurisdiccional supremo en todos los órdenes, salvo en garantías constitucionales (artículo 123.1, CE). Resta por resolver lo que pueda ocurrir en las elecciones locales.

\section{La integración de la legalidad electoral secundum Constitutionem. La ficción de imponer al órgano judicial el deber de integrar la ley conforme a la Constitución en vez de declarar la inconstitucionalidad}

¿Integración de la ley electoral conforme a la Constitución o declaración de inconstitucionalidad? Expliquemos con más calma la cons-

${ }^{29}$ La Ley Reguladora de la Jurisdicción Contencioso Administrativa de 1998 vino a modificar en parte las cosas (artículos 6o. a 13), al cambiar las competencias de los órganos judiciales y crear juzgados unipersonales de lo contencioso, con una competencia para conocer de impugnaciones en materia de proclamación de candidaturas (artículo 4), pero no de electos; siguen siendo las Salas, por su importancia, quienes enjuician los recursos contra acuerdos de proclamación de electos (artículo 10.1.f). Las propuestas de reforma de la LOREG de 2010 de la Comisión de Asuntos Constitucionales atribuyen el recurso ante las resoluciones de la Oficina del Censo Electoral a los jueces unipersonales de lo contencioso en vez de como hasta ahora a los jueces de primera instancia, lo que es una atribución lógica por razón de la materia y de los actos impugnados. 
Esta revista forma parte del acervo de la Biblioteca Jurídica Virtual del Instituto de Investigaciones Jurídicas de la UNAM

trucción seguida en la reseñada STC 24/1990. Comienza el Tribunal, muy correctamente, admitiendo que el amparo electoral no es una apelación y que un derecho de configuración legal debe ser ejercido con arreglo a los requisitos legales que lo integran, pero admitiendo que $l a$ interpretación de esa legalidad hecha por los Tribunales ordinarios no debe ser revisada in toto (F. $2{ }^{\text {a }}$ ). Distingue luego entre el alcance que deba concederse al derecho fundamental del artículo 23.2, cuando se habla de cargos funcionariales, de cuando se refiere a aquéllos de naturaleza representativa, respecto de los primeros, es un derecho de carácter reaccional para preservar la igualdad, en los segundos, los requisitos que señalen las leyes no sólo no pueden quebrar la igualdad sino tampoco producir "otro género de inadecuación"; por eso, el litigio debe contemplarse, además de desde el ángulo de la igualdad, desde la garantía de la mayor efectividad de los derechos fundamentales que están en la base de los órganos representativos. Al llegar aquí, se produce un giro en la argumentación, y se afirma que para no degradar los derechos fundamentales en juego, debe examinarse: "Si la interpretación de la legalidad configuradora de los derechos fundamentales se ha llevado a cabo secundum Constitutionem".

Es este discutible fundamento teórico el que después permitirá al Tribunal decirle al órgano judicial que debía haber hecho una interpretación integradora del artículo 113 LOREG conforme a la Constitución, y considerar que, omitiéndola, había vulnerado el derecho fundamental de los candidatos (F.J. $6^{\circ}$ ).

La construcción no es distinta de la que el propio Tribunal ha seguido en materia de leyes procesales y tutela judicial efectiva, otro derecho fundamental de configuración legal, con resultados conocidos y allí muy discutidos por la inseguridad jurídica que produce al zurcir las viejas leyes procesales en vez de impulsar su modificación. Pero acaso no sea adecuada por varias razones que intentaré enumerar esquemáticamente.

En primer lugar, una cosa es que la interpretación ofrecida por el Tribunal ordinario y la declaración de nulidad de la elección en toda la circunscripción "afectase", sin duda, al sufragio pasivo de los candidatos no proclamados, y otra bien distinta es que "vulnerase" y lesionara el derecho fundamental ex artículo 23.2 de la Constitución, lo cual supone un salto lógico en el razonamiento. ${ }^{30}$ Una decisión judicial

30 Según razonó Pérez Royo, Javier, op. cit. 
Esta revista forma parte del acervo de la Biblioteca Jurídica Virtual del Instituto de Investigaciones Jurídicas de la UNAM

basada en un precepto legal, técnicamente incorrecta, pero motivada conforme a derecho, no puede lesionar derecho fundamental alguno. Así se ha admitido en la propia tutela judicial efectiva, al señalar $v . g r$. que la selección razonada de la norma legal aplicable y su interpretación normalmente - salvo excepciones-constituyen problemas de estricta legalidad.

En segundo lugar, menos aún la Constitución puede imponer a un órgano judicial una interpretación "manipuladora" de un precepto legal tal que le obligue a decir lo que manifiestamente no decía. La interpretación correctora y conforme a la Constitución de las leyes que el artículo 5o. de la Ley Orgánica del Poder Judicial impone a jueces y tribunales posee un límite infranqueable en el margen concedido por el tenor literal de las mismas, según advirtió con agudeza el voto particular. Otra vez volvió a cometerse el mismo error o ficción jurídica que en numerosas sentencias en las que se aplica la tutela judicial efectiva: imputar al juez la lesión de un derecho fundamental que, en realidad, comete la ley; por supuestamente desfallecer aquél en intentar una discutible interpretación correctora que, difícilmente, un juez de instancia osaría efectuar por elementales razones de prudencia y sometimiento a la ley. Es ésta una carga que ni en uno ni otro derecho fundamental creo sensato continuar arrojando sobre las espaldas de jueces y tribunales en vez de verter directamente sobre el legislador. ${ }^{31}$

En definitiva, si el Tribunal Constitucional estimaba inconstitucional el artículo 113 LOREG, apartados 2, letra $d$, y 3, por resultar desproporcionada la sanción que imponía, el vicio estaba directamente en la ley y no en la resolución judicial, probablemente debió plantearse una autocuestión de inconstitucionalidad (artículo 55.2 LOTC) y declarar su inconstitucionalidad para que fuera corregida por el legislador. Bien es cierto - seamos realistas-, que en este concreto caso, el vacío legal hubiera hecho más difícil una futura y pronta convocatoria electoral. Pero todos sabemos lo rápido que se aprueban las leyes - por trámite de urgencia, en lectura única... - cuando la ocasión aprieta y

${ }^{31}$ La misma idea fue defendida en abstracto por Cruz, Pedro, "El recurso de amparo constitucional: el juez y el legislador", en varios autores, Los procesos constitucionales, Madrid, CEC, 1991, pp. 17 y ss. Muy rotundamente, defendía la divisa "Menos amparo frente al juez, más amparo frente al legislador”. Un juicio muy lógico que comparto, desde la lógica interna de un sistema de jurisdicción constitucional y control normativo, pero que no ha acabado de hacer suyo su único posible destinatario, el Tribunal Constitucional; tampoco durante la presidencia posterior del propio Pedro Cruz. 
los grupos parlamentarios alcanzan consensos; de manera que no me parece un obstáculo insalvable. La opción entre interpretación integradora de la ley electoral con la Constitución, construyendo normas subconstitucionales, o la declaración de inconstitucionalidad y nulidad sigue siendo un dilema nada sencillo de resolver para el intérprete supremo de la Constitución.

En síntesis, la solución que se habría producido de mantenerse el pronunciamiento del Tribunal de Murcia hubiera sido procesal, política y económicamente costosa, pero no inconstitucional ni, sobre todo, lesiva del derecho fundamental: único extremo que podía discutirse en el amparo constitucional. El debate no está obsoleto, una vez operada la reforma de la LOREG en 1991, el problema se amortigua, pero no desaparece, y conviene discutir si la excepcionalidad del caso resuelto en esa sentencia, condicionado por las graves circunstancias de gobernabilidad existentes en aquellos momentos y a las que el Tribunal Constitucional atendió, permite erigir en normalidad el manejo del mismo criterio. El legislador debería responder de sus propios vicios de inconstitucionalidad en vez de imputar fingidamente la lesión al juez.

\section{La relación causal entre irregularidades invalidantes y fallo anulatorio. Irregularidades consideradas en su conjunto}

En la sentencia sobre la circunscripción de Melilla y en las mismas elecciones generales de 1989 (STC 25/1990), se enjuiciaron diversas irregularidades acaecidas en ese distrito electoral que, consideradas en su conjunto, llevaron al Tribunal Superior de Justicia de Andalucía a anular en su totalidad la elección.

El Tribunal Constitucional desestimó el recurso de amparo y efectuó algunas interesantes consideraciones (F.J. $6^{\circ}$ ) sobre el alcance de las irregularidades enjuiciables en amparo. Aseveró que debe -cuando se le solicita por los legitimados- revisar la valoración jurídica que de los hechos ha llevado a cabo el órgano judicial con el fin de comprobar si ha ponderado adecuadamente los derechos fundamentales en juego. No cabe, pues, admitir — según pretendía el Ministerio Público-que, determinar si procedía declarar la nulidad o no de la 
Esta revista forma parte del acervo de la Biblioteca Jurídica Virtual del Instituto de Investigaciones Jurídicas de la UNAM

elección, sea una tarea que no rebase el ámbito de la estricta legalidad irrevisable en amparo.

Dicho esto el Tribunal insistió también en la necesidad de interpretar la legalidad configuradora de los derechos fundamentales secundum Constitutionem, recuperando, a mayor abundamiento, una argumentación muy del gusto de los primeros años de la justicia constitucional y a todas luces excesiva: "Nada que concierna al ejercicio por los ciudadanos de los derechos que la Constitución les reconoce, podrá considerarse nunca ajeno a este tribunal (STC 76/1981, F.J 4. ${ }^{\circ}$ )".

Aprovechando la ocasión, se definieron los derechos fundamentales de configuración legal como aquellos que la "delimitación de su contenido y perfiles concretos queda encomendada a la ley" (ibidem). Una definición que he discutido fuertemente en mis trabajos, por su escasa consistencia argumental, demandando un mayor esfuerzo de motivación en las sentencias, pero que ha acabado por consolidarse en la jurisprudencia sin mayores explicaciones. ${ }^{32}$

Tras estas afirmaciones genéricas, el Tribunal recordó el principio de conservación de los actos válidamente celebrados (F.J. $6^{\circ}$ ), criterio ya usado en la STC 24/ 1991, y entró a analizar (F.J. 7o.) la "relación causal" presente entre "irregularidades invalidantes" y "fallo anulatorio", estimando que esa relación existía en un grado suficiente. ${ }^{33}$

Hubo pues una valoración conjunta de la prueba por el tribunal ordinario que el pleno del Tribunal Constitucional aceptó como válida, considerando que tenía "suficiente rigor lógico", y concluyendo —en una plausible autocontención- que no le correspondía contradecir esa valoración con una revisión del expediente electoral (F.J. $8^{\circ}$ ).

32 Véase, para un desarrollo de esta crítica, García Roca, Javier, Cargos públicos representativos..., cit., epígrafe “¿A qué llamamos derecho fundamental de configuración legal? Una hidra de mil cabezas”, pp. 179-192.

33 Interesa destacar que dichas irregularidades eran muy variadas. Dos lo eran de carácter general y relativas, respectivamente, una a haber recibido el partido político recurrente una lista incompleta del censo electoral, lo que pudo perjudicar su relación con los electores, y la segunda, a la utilización abusiva de Mesa auxiliares alejadas de las cabinas electorales para depositar sobres y papeletas, que es una posibilidad excepcional en la Ley electoral, limitada a cuando el número de candidaturas exceda al de disponibilidades de las casillas en las cabina, cuestión que pudo afectar al secreto del sufragio. La Sala de procedencia consideró de relevancia la segunda irregularidad y limitó la importancia de la primera de cara a determinar la nulidad de la elección. Y estimando conjuntamente esta tacha genérica junto a otras específicas irregularidades en varias Secciones o Mesas declaró la nulidad de elección. 
Esta revista forma parte del acervo de la Biblioteca Jurídica Virtual del Instituto de Investigaciones Jurídicas de la UNAM

También el Tribunal Europeo de Derechos Humanos ha hecho en algunas ocasiones una valoración conjunta de las irregularidades electorales. De manera que la posibilidad no puede desecharse a priori. Sin embargo, debe ser una opción excepcional, entre otras razones, por respeto al principio de legalidad. No olvidemos que estamos ante una forma de valoración conjunta de los hechos y de practicar la prueba que un importante sector doctrinal -y la propia jurisprudencia constitucional- ha criticado en el orden jurisdiccional penal, puesto que dificulta notablemente cualquier instancia revisora ulterior $y$ puede no ser suficiente para desvirtuar la presunción constitucional de inocencia. Pero, en otro contexto, en materia electoral, dada la naturaleza de un procedimiento tan complejo y no siempre en manos de profesionales, podría resultar inevitable este tipo de valoración global en algunos supuestos.

Conviene asimismo reservar para nuestro fines la "relación causal" entre "irregularidades invalidantes" y "fallo anulatorio" que el Tribunal explicita y acoge. Así una irregularidad electoral acaba por tener relevancia constitucional si alcanza un grado determinante del resultado electoral y, en consecuencia, permite dictar un fallo anulatorio de la elección, en todo o en parte. La invalidez deriva del condicionamiento o falseamiento del resultado, el camino puede recorrerse en ambos sentidos de la relación, pero suele hacerse a la inversa. Un criterio de bastante sencilla aplicación.

Como segunda conclusión, parece existir una irregularidad invalidante que lleva a la declaración de nulidad como consecuencia de un conjunto de irregularidades valoradas globalmente. ${ }^{34}$

${ }^{34}$ El Tribunal Europeo de Derechos Humanos en bastantes ocasiones ha hecho una valoración conjunta de las irregularidades. En el importante caso del Partido Laborista de Georgia, del 8 de julio de 2008, disculpó algunas irregularidades electorales, con tolerancia y realismo, por tratarse de las primeras elecciones libres en una transición a la democracia, "de manera que rasgos que serían inaceptables en un contexto puedan ser aceptados en otro" (65). La sentencia analiza, siguiendo un relevante método de Derecho comparado, las sensibles diferencias en la Administración y el procedimiento electorales de los Estados europeos. 


\section{Los errores irrelevantes en el cómputo tienen distintas consecuencias que el fraude electoral. Principio de conservación de los actos. Electores y votantes}

En cambio, en la circunscripción de Pontevedra, STC 26/1990 se otorgó el amparo en un supuesto en el cual se discutían las irregularidades $^{35}$ acaecidas en la Mesa de residentes ausentes y en una Mesa de Vigo. En la primera, se computaron más votos que el número de electores que efectivamente habían votado. Planteado un recurso, el Tribunal Superior de Justicia de Galicia lo estimó y anuló la elección en la Mesa de residentes, en aplicación del artículo 105.4 LOREG que, en su redacción de 1985, decía: "Cuando el número de votos que figure en un acta exceda al de los electores de la Mesa, con la salvedad del voto emitido por los interventores, la Junta tampoco hará cómputo de ellas".

El Tribunal Constitucional aceptó la interpretación propuesta por la parte actora (F.J. $6^{\circ}$ ), de acuerdo con una exégesis sistemática del artículo 105.4 LOREG en relación con otros artículos de la misma ley, y resolvió que cuando allí se emplea la palabra "electores" se hace con un uso claramente distinto y diferenciado del de "votante" y quiere decirse quienes ostentan la capacidad electoral, independientemente de que ejerzan o no su derecho. Se destacó que el principio de conservación de los actos aparece como preeminente y, en consecuencia, el mandato del citado artículo 105.4, dirigido a las Juntas electorales, debe entenderse orientado a excluir únicamente cualquier caso de manipulación o fraude electoral y no simples irregularidades en el cómputo, circunstancia que justifica que órganos no jurisdiccionales, como son las Juntas, excluyan del cómputo final los resultados de determinadas Mesas.

Como la discusión en el cómputo se centraba en los votos nulos (33 en lugar de 65), se concluyó diciendo que la constatación de un exceso de 32 votos sobre un total de 4882 , de los cuales 4850 no merecían

35 Para comprender bien el pronunciamiento conviene conocer con algún detalle el supuesto de hecho, en concreto, las irregularidades acaecidas en la Mesa de residentes ausentes: electores de la Mesa, 14240; volantes, 4850; votos válidos 4817; nulos, 65; en blanco, 13. El número de votos computados (4882) era, pues, superior al de votantes (4850), por error en el cómputo. 
ningún reproche, no justificaba la nulidad de la elección. Otro tanto semejante se dijo (F.J. $8^{\circ}$ ) respecto de la Mesa de Vigo donde el exceso era de un voto.

El legislador de 1991 modificó la LOREG en su artículo 105.4, a resultas de la experiencia adquirida en este caso, añadiendo que si en alguna Mesa hubiere actas dobles y diferentes o cuando el número de votos que figure en un acta exceda al de los electores que haya en la mesa "según las listas del censo y las certificaciones usuales presentadas", con la salvedad del voto emitido por los Interventores, la Junta tampoco hará cómputo de ellas "salvo que existiera error material o de hecho o aritmético, en cuyo caso procederá a su subsanación”. Los entrecomillados reflejan las adiciones al texto legal.

Partiendo del dato de que el caso arrancaba de un claro error material o aritmético, la cuestión se matizó y se hizo constar esta excepción en la ley, sin necesidad de agregar qué debe entenderse por "electores" o su diferenciación con los "votantes", que son conceptos legalmente nítidos, y más aún después de la sentencia precitada.

\section{$X$. El rechazo de interpretaciones formalistas enervantes del sufragio pasivo y de la votación mayoritaria} de un candidato. Declaraciones de nulidad retrotrayendo a momentos posteriores al de la votación

La última de las sentencias dictadas en amparos de proclamación de electos en las elecciones generales de 1989 y que considero conveniente comentar fue la STC 27/1990, relativa a la elección de un senador por Ávila.

El Tribunal Constitucional otorgó el amparo solicitado por un candidato del PP y anuló la sentencia dictada por el Tribunal Superior de Justicia de Castilla y León, pero sin declarar nula la elección, simplemente retrotrayendo las actuaciones al momento antes de dictarse sentencia, para que la Sala entrase a valorar motivadamente la validez o invalidez del acta de la Mesa de Mamblas, y adjudicara el escaño a quien correspondiera.

El supuesto se refería al derecho del candidato del PP a mantener la condición de candidato electo - que le atribuía la Junta Electoral y le privó la sentencia - y, para ello, al cómputo de los votos de la citada 
Mesa, que la Sala consideró intrascendente. Respecto del primer problema, la Sala de procedencia estimó en parte el recurso contenciosoelectoral interpuesto por el CDS contra la proclamación de ese candidato, después de efectuar un recuento de votos a la vista del expediente electoral, entendiendo que, pese a ser el candidato del CDS menos votado que el del PP, le correspondía el escaño, en aplicación del artículo 108.1 LOREG, que manda que, una vez concluido el escrutinio, se presenten las reclamaciones en el plazo de dos días, coligiendo de ahí que la falta de reclamación tempestiva era igual a aquietarse o a consentir la decisión adoptada e impedía acceder al contencioso-electoral. Por consiguiente, la Sala atribuyó al candidato del CDS los votos que realmente le correspondían en su cómputo, y, en cambio, al candidato del PP únicamente los que le computó la Junta.

La interpretación seguida por el tribunal ordinario era tan equivocada que, rápidamente, el Tribunal Constitucional llegó en su sentencia a la conclusión de que constituía una interpretación formalista de los artículos 108.1 y 112 LOREG: "Irrazonable y contraria al espíritu de la propia ley" (F.J. $3 .{ }^{9}$ ), pues no es lógico pedir que reclame quien se ve favorecido por el resultado del escrutinio.

El Tribunal Constitucional, en primer lugar, analizó el artículo 70.2 CE para dejar claro que, pese a que la validez de las actas y credenciales de los miembros de las cámaras esté sometida al control judicial, ni este precepto constitucional, ni ningún otro excluye la revisión que pueda realizarse en vía de amparo para otorgar efectividad a los derechos fundamentales (F.J. $3^{\circ}$ ).

Una afirmación muy taxativa, pero provista, de una fundamentación endeble, puesto que, otra vez, se dijo que "nada que concierna al ejercicio de los derechos que a los ciudadanos les concede la Constitución, podrá considerarse nunca ajeno a este Tribunal" (STC 26/1981, F.J. $14^{\circ}$ ). Un aserto con indudable valor como consigna, pero provisto de numerosas excepciones, y carente de suficiente rigor jurídico para erigir un verdadero criterio de decisión.

No obstante, con mayor acierto, allí mismo se completó ese razonamiento diciendo que se vulneraba el derecho de sufragio activo y pasivo (artículo 23.1 y 2), piedra angular del sistema democrático, cuando:

Demostrada la votación mayoritaria de un candidato respecto de otro, se hacía la proclamación en favor de este último en virtud de una argumenta- 
ción - conviene percatarse de este inciso- que contradice abiertamente el sistema electoral y la Ley Orgánica que lo regula.

Es muy probable que, revocando la muy forzada interpretación de los artículos 108.1 y 112.1 LOREG hecha por el Tribunal Superior, errónea y lesiva de ambas clases de sufragio, el Tribunal Constitucional no errara y actuara adecuadamente. En cualquier caso, el precitado artículo 108 LOREG es uno de los que mayores modificaciones ha sufrido en la reforma de 1991, dada su importancia, detallándose en la actual regulación legal el contenido del acta de escrutinio, el procedimiento para las reclamaciones y protestas y para su resolución y la forma de efectuarse el acta de proclamación.

\section{Votos nulos y principio de inalterabilidad de las listas ${ }^{36}$}

\section{Enumeración tasada de los supuestos de nulidad y supuestos implícitos}

La STC 167/1991 (F.J. 4º) aclaró que los supuestos de nulidad que contiene el artículo 96 LOREG no son ad exemplum sino tasados. Pero sin cerrar la puerta a algún excepcional supuesto implícito.

\section{Papeletas tachadas en el Congreso de los Diputados y exigencia rigurosa del principio de inalterabilidad de las listas}

Quiero destacar un par de resoluciones relativas al principio de inalterabilidad de las listas del artículo 96.2, LOREG, precepto en el cual se especifica que deben entenderse como votos nulos las papeletas en las que se hubiere modificado, añadido, señalado o tachado nombres de los candidatos. Una consecuencia del carácter cerrado y bloqueado de las listas al Congreso de los Diputados, que ha llevado a robustecer el rigor en el cumplimiento de esta exigencia.

${ }^{36}$ Véase Duque, Juan Carlos, Elecciones políticas y Tribunal Constitucional. Jurisprudencia constitucional 1908-2005, cit., pp. 454 y ss. 
Esta revista forma parte del acervo de la Biblioteca Jurídica Virtual del Instituto de Investigaciones Jurídicas de la UNAM

La STC 156/1991, frente a la pretensión del representante de la candidatura actora, consideró que no era irrazonable ni desprovista de motivación la interpretación hecha por la Sala de procedencia, la cual asimiló, a señalar o tachar nombres de los candidatos, una papeleta con líneas cruzadas o rayas, entendiendo que se trataba de una alteración de la lista, y declarando nulas las papeletas (F.J.2 ${ }^{\circ}$ ). Este criterio se mantuvo en la STC 165/1991, donde el Tribunal Constitucional advirtió que el entendimiento de este artículo 96.2 LOREG se trataba de una cuestión de legalidad electoral y reconoció que la interpretación ofrecida por la Sala no era irrazonable o arbitraria. Así como en la STC 115/1995 respecto de una papeleta garabateada.

No obstante, la Junta Electoral Central y el resto de las Juntas Electorales evitaron una interpretación excesivamente formalista del precepto legal en casos de alteraciones irregulares pidiendo que se procediera a indagar la voluntad efectiva del elector, aplicando - de forma discutible- el principio de interpretación más favorable al ejercicio del derecho fundamental.

Pero, tras las elecciones locales de 2007, la STC 167/2007 (FF.J. 7 y 8), una doctrina reproducida en las SSTC 168 a 170/2007, adoptaron un criterio diferente a la búsqueda de la seguridad jurídica, pues, tras recordar que se trata de una cuestión de legalidad, advirtieron de las numerosas dudas que provocaba la exégesis del precepto, dada la amplia diversidad de soluciones adoptadas por la Administración electoral y los órganos jurisdiccionales, todo lo cual llevó a insistir en la necesidad de preservar y exigir el principio de inalterabilidad de las listas electorales con más rigor, lo que debe preceder en un orden lógico al principio de conservación de los actos y al de la interpretación más favorable. En tres de estas sentencias, el Tribunal corrigió lo acordado por la Junta Electoral Central que dio por válidas papeletas con una cruz o aspa al lado del nombre de un candidato, atendiendo a la voluntad del elector.

Vinculada por esta jurisprudencia constitucional, la Junta Central corrigió su criterio, adaptándose a la nueva doctrina con su Instrucción 12/2007, del 25 de octubre - que puede leerse en su web-dirigida a las Mesas y Juntas Electorales. Claro está que con la excepción de las elecciones al Senado donde el elector debe marcar a los candidatos. Obsérvese la interesante interacción entre legislador, Tribunal Constitucional y Junta Electoral Central.

A mi entender el nuevo criterio es correcto, pese a que pueda parecer injusto, pues es menester preservar los principios de seguridad ju- 
rídica y de igualdad que son esenciales en un procedimiento electoral ante una pluralidad de operadores muy grande.

\section{Papeletas tachadas en Senado}

Esta exigencia es más flexible, según el artículo 96, apartado 3, LOREG, que regula la determinación de la nulidad de los votos para el Senado, una decisión condicionada por la necesidad de que el elector marque en la papeleta tres votos dentro de una larga lista sábana, lo que hace más probable $-\mathrm{y}$ razonable - la posibilidad de rayas, cruces o tachaduras en virtud de errores frente a lo acecido en las elecciones al Congreso y las locales donde las candidaturas son cerradas y bloqueadas. Ello hace que, en buena lógica, deba ser también distinto el rigor con el que se enjuicie la presencia de estas marcas (STC 165/1991, F.J. $3^{\circ}$ )

\section{Votación mediante papeleta correspondiente a otra circunscripción}

Un curioso supuesto (STC 167/1991, FF.J. 3 a 5) deriva de la habitual práctica del mailing por los partidos políticos o envío de las papeletas al domicilio de los electores por correo. Un error masivo llevó a enviar, en las elecciones locales, papeletas del mismo partido, pero correspondientes a otro municipio, lo que indujo a que los electores depositaron confiadamente en las urnas papeletas equivocadas sin advertir el error. Una extravagante hipótesis de nulidad que, claro está, el artículo 96 LOREG no contemplaba. Las Juntas Electorales y tribunales presumieron el error y reconstruyeron la voluntad o intención de votos de los electores, convalidando sus votos. Pero el Tribunal Constitucional estimó el amparo y declaró lesiva esa interpretación de los derechos de los demás candidatos a acceder en condiciones de igualdad; alegando que rompe esa igualdad atribuir votos a una de las listas en liza que sus concretos candidatos no recibieron.

A mi entender este razonamiento y el fallo no pueden ser fácilmente compartidos, ya que distan de ser razonables. Pues, sin necesidad de adentrarse en la cuestión de fondo, esto es, si la representación es por partidos o por concretos candidatos, debió previamente ponderarse 
Esta revista forma parte del acervo de la Biblioteca Jurídica Virtual del Instituto de Investigaciones Jurídicas de la UNAM

que los propios partidos que presentan las candidaturas indujeron a error a los electores mediante su equivocación en el mailing. Y, en consecuencia, debió estarse a la voluntad real de los electores en el sentido de su sufragio al elegir las candidaturas de un partido, despojando esta inequívoca voluntad del manifiesto error en los candidatos.

\section{La posibilidad de la revisión directa del escrutinio o la necesidad de retrotraer al órgano judicial}

La Sala Primera del Tribunal Constitucional, en la STC 157/1991, examinó un supuesto en el cual la demanda aducía errores materiales, al transcribir al acta del expediente electoral los resultados, consecuencia del error padecido por los miembros de la Mesa. El Tribunal Superior de Justicia de Canarias, de manera muy formalista, no se pronunció sobre esta cuestión de fondo por no haber satisfecho el recurrente el requisito del artículo 108.2 LOREG, consistente en hacer constar la denuncia o reclamación en el acta de escrutinio.

El Tribunal Constitucional con buen criterio otorgó el amparo, por entender rigorista la interpretación hecha del artículo 108.2, y revisó directamente el escrutinio, subsanando esos errores materiales y declarando los resultados reales. Si bien como retrotrayendo a la Sala de procedencia, a los exclusivos efectos de que dictase la declaración de electos de acuerdo con ese cómputo. Se argumentó, para dictar esa parte dispositiva, que, cuando coexisten lesiones del artículo 24 y a la vez de otros derechos fundamentales, puede entrarse directamente a la vulneración de los mismos (F.J. $6^{\circ}$ ).

En los fundamentos anteriores de la misma STC 157/1991, se insistió en la idea de que es prioritaria la búsqueda de la verdad material, ${ }^{37}$ manifestada en las urnas por los electores (STC 24/1990), y en que los tribunales contencioso-electorales deben revisar plenamente las irregularidades electorales (STC 26/1990). Esta segunda afirmación es indudable, pero puede que resulte contradictoria con la primera.

37 Sobre el mandato dirigido a los órganos judiciales de impedir el falseamiento de la voluntad popular y cómo se recoge esta doctrina en la jurisprudencia de aquéllos, véase Álvarez Conde, Enrique, "Los principios del derecho electoral", Revista del Centro de Estudios Constitucionales, núm. 9, 1991, pp. 9 y ss. 


\section{Epílogo: el Tribunal Constitucional como garantía electoral y el solapamiento de las jurisdicciones electoral y constitucional}

Me centraré en las conclusiones en el caso español, si bien llamaré asimismo la atención sobre las modestas reflexiones desde la perspectiva comparada que se han hecho en el epígrafe 3 sobre México a donde ahora reenvío.

Hace una década este epígrafe aparecía formulado como un interrogante. Pues el alcance del derecho fundamental de acceso a los cargos públicos representativos en materia de garantías electorales y regularidad del procedimiento electoral tiene respuestas doctrinalmente controvertidas, dada la naturaleza del derecho fundamental como de configuración legal. Me preguntaba en 1999 si el Tribunal Constitucional era un tribunal electoral, la respuesta es de tiempo en tiempo más claramente afirmativa. El Tribunal rechaza en línea de principios que le corresponda interpretar las normas electorales, pero cuando lo estima pertinente para preservar ambas modalidades del derecho de sufragio no duda en armonizar criterios.

Después del análisis de la jurisprudencia que se ha hecho, varias hipótesis son posibles. Primero, una absoluta confusión de jurisdicciones, reconocer que prácticamente toda la ley electoral es contenido de este derecho fundamental de mediación legal, ${ }^{38}$ forma parte del contenido protegido por el derecho fundamental y es tutelable en amparo constitucional. Segundo, diferenciar entre lo que sería el "desarrollo directo" del derecho fundamental (reserva de Ley Orgánica del artículo 81.1, CE) y lo que no lo es, al configurar meras condiciones de ejercicio (artículo 53.1, CE), lo que permitiría distinguir entre el control de la regularidad electoral que corresponde a la Administración electoral y posteriormente a la jurisdicción contencioso-electoral, y aquellos aspectos que incumben, como excepción, a la jurisdicción constitucional en cuanto tutela del derecho fundamental al sufragio.

${ }^{38}$ Lo que no parece que sea siquiera la solución seguida en línea de principios por el propio Tribunal Constitucional, que en bastantes ocasiones ha reconocido - como se ha visto- que existen irregularidades formales y vicios no invalidantes de la elección y, por tanto, sin relevancia o dimensión constitucional. 
Esta revista forma parte del acervo de la Biblioteca Jurídica Virtual del Instituto de Investigaciones Jurídicas de la UNAM

Y, tercero, la situación actual, que podríamos calificar como solución intermedia o ecléctica: mantener a nivel teórico o de principios que no existe una confusión de jurisdicciones y que no es competencia del Tribunal Constitucional la interpretación de las normas electorales, pero concurrir con los tribunales contenciosos en unas mismas funciones según se deduce del empleo de un criterio de deslinde cuantitativo: cuando la irregularidad es determinante del resultado electoral.

Para preservar el sufragio pasivo y en amparos de proclamación de candidaturas (la vía del artículo 49, LOREG), la jurisprudencia constitucional ha revisado múltiples irregularidades: denominaciones, siglas y símbolos; la forma de autenticar las firmas por una agrupación de electores; la rectificación de un candidato que era a la vez administrador electoral; la imposibilidad de distinguir entre "irregularidades" y "defectos sustantivos", así como la necesidad de que las Administraciones electorales favorezcan la subsanación de las candidaturas, con el límite de la prohibición de su modificación.

En cualquiera de estos bloques de problemas - causas de inelegibilidad y de incapacidad electoral y requisitos para la proclamación de candidaturas-, no parece que pueda objetarse, en líneas generales, la extensión o el alcance de los vicios, lesivos del derecho fundamental, que han sido revisados en el amparo constitucional. Pues, en todos estos extremos, la directa conexión de los requisitos legales con el acceso a los cargos públicos mediante la elección es sumamente estrecho. Sería una posición extremadamente formalista, y, por ello, indefendible cuando de garantizar derechos fundamentales se trata, predicar una mayor autocontención del Tribunal Constitucional.

Es obvio que una interpretación rigorista de los requisitos para la proclamación de candidaturas por la Administración electoral o los juzgados o tribunales contencioso-administrativos lesionaría el derecho fundamental en su vertiente nuclear: el libre e igual acceso a la elección. Comprobar que los requisitos legales sean adecuados a la Constitución y a la finalidad que la representación preserva - traducir a escaños y cuotas de poder político las preferencias de los ciudadanos- es una exigencia impuesta por el derecho fundamental que nos ocupa. De manera que - aunque los efectos nos lleven a las causas-, incapacidad, inelegibilidad e incompatibilidad, así como los requisitos para la proclamación de las candidaturas estimo que son desarrollo directo y contenido nuclear del derecho de acceso a los cargos públicos. Una conclusión relevante. 
Esta revista forma parte del acervo de la Biblioteca Jurídica Virtual del Instituto de Investigaciones Jurídicas de la UNAM

Mucho más enrevesado es adoptar una posición sobre la jurisprudencia dictada en amparo de proclamación de electos (artículo 114 LOREG), que hemos aquí reseñado, es decir, qué clases de irregularidades pueden ser tuteladas en esta vía y determinar la nulidad por considerarse invalidantes. Las sentencias constitucionales han manejado en la mayoría de las ocasiones el criterio de que cualesquiera irregularidades, si son determinantes del resultado de la elección, son revisables. Se garantiza así que se proclamen los candidatos que realmente fueron preferidos por el cuerpo electoral. Una tendencia que ha acabado por consolidarse en los últimos dos lustros. Este criterio cuantitativo, a la hora de distinguir entre meras irregularidades electorales e irregularidades invalidantes, ha llevado a revisar la interpretación de la legalidad electoral hecha en numerosos aspectos por los tribunales ordinarios y a veces, hasta a cerciorarse de los hechos.

Con el simple afán de corroborar esta afirmación, se han enjuiciado, entre otros, los siguientes extremos: el alcance de una declaración judicial de nulidad de una elección estimando que, salvo que en el fallo se diga otra cosa, "nueva convocatoria" es una "nueva elección" en todas sus fases; errores materiales en la transcripción de las actas en cada uno de los sobres o en el cómputo de votos; la utilidad del segundo sobre; el alcance total o parcial, en toda la circunscripción o sólo en unas Mesas, de la declaración judicial de nulidad de la elección en función de las irregularidades advertidas; la revisión misma de la relación causal existente entre irregularidades supuestamente invalidantes y el fallo anulatorio, v. gr., si el abuso y uso indebido de las Mesas auxiliares incide o no en el secreto del voto; la exégesis del mandato del artículo 105.4 LOREG referido a que no se computen las actas en las que haya más votantes que electores; qué papeletas deben considerarse o no como votos nulos por estar rayadas, y un largo etcétera.

Normalmente, el manejo de este criterio cuantitativo se justifica diciendo - especialmente desde las elecciones generales de 1989que la legalidad electoral debe interpretarse por los tribunales ordinarios secundum Constitutionem para no degradar el derecho fundamental. Y, aunque suele añadirse que esto no permite su revisión in toto, en realidad, cualquier irregularidad que pueda afectar de manera determinante al resultado de la elección viene revisada. Podría decirse que cual si se tratara del acceso a un recurso judicial en razón de la cuantía del litigo; la imagen es casi la misma. Esta jurisprudencia ha acabado por hacer del amparo constitucional prácticamente una garantía más en materia electoral. 
Esta revista forma parte del acervo de la Biblioteca Jurídica Virtual del Instituto de Investigaciones Jurídicas de la UNAM

Sin resultar sencilla cualquier propuesta de sustitución de este criterio, su manejo no deja de producir cierta insatisfacción conceptual. Habría que distinguir, por razón de la naturaleza de los vicios, entre aquellas irregularidades acaecidas en el proceso electoral y que excepcionalmente resulten ser directamente lesivas del derecho fundamental, y otras cuya interpretación - la mayoría- debería corresponder exclusivamente a la Junta Electoral Central y luego al Tribunal Supremo en su posición de revisión de la plena regularidad del procedimiento electoral. Una singularización de los vicios que únicamente podría hacerse caso a caso y mediante una jurisprudencia muy matizada. Razonando en abstracto - a mi juicio- la revisión de ciertos problemas fácticos o de legalidad —el cómputo, la reconstrucción fáctica, la validez o nulidad de las papeletas, las discrepancias entre actas o sobres, y otros extremos análogos-, que ya han sido plenamente enjuiciados previamente por los órganos de la jurisdicción contencioso electoral, no parecen configurar vicios que, por su propia naturaleza, puedan erigirse en una directa violación del derecho fundamental, por mucho que, sin duda, le afecten. Desde esta autocontención, la revisión en el amparo constitucional de esa clase de irregularidades legales sólo sería posible, excepcionalmente, si la interpretación judicial estuviera fundada en notorio error, arbitrariedad en la conclusión judicial alcanzada, ausencia de motivación, etcétera. Alguna consecuencia debería tener que ya haya habido una revisión judicial del conflicto electoral en dos instancias.

La jurisprudencia constitucional, sin embargo, no ha ido habitualmente por esta línea en tres décadas y esto hace que el debate académico comience a ser estéril y que debamos aceptar la tozudez de los hechos. Mas no puede ocultarse que no es sencillo encontrar una razón por la cual la ley electoral configura casi siempre un desarrollo directo del derecho fundamental y no una mera regulación de las condiciones que hacen posible su ejercicio. Decir que nada que tenga que ver con los derechos fundamentales es ajeno a la competencia del Tribunal Constitucional, pese a lo expresivo de esa voluntarista declaración de principios, no parece un razonamiento convincente. Puesto que una cosa es que un problema afecte a uno de esos derechos, es decir, incida en su ejercicio, y otra bien distinta, aseverar que produzca una lesión constitucional, esto es, que viole el núcleo del derecho. Y asegurar que la legalidad electoral debe ser interpretada secundum Constitutionem es todavía menos una justificación del fenómeno, porque más allá del 
normal juego del favor libertatis - criterio harto arriesgado en materia de derechos fundamentales-, tan conforme con la Constitución es que el segundo sobre pueda ser reclamado por las Juntas electorales como que no ocurra así y sea únicamente utilizable en el contencioso electoral. Por lo demás, el principio jurídico de conservación de los actos jurídicos válidamente realizados, menos aún, creo otorgue dimensión sustantiva de lesión de un derecho fundamental a cualesquiera de sus hipotéticas transgresiones.

Ha acabado por imponerse en la jurisprudencia del Tribunal Constitucional una posición muy pragmática y qué duda cabe que garantista del derecho de sufragio y de la limpieza de la elección: la superposición de controles. El precio es doble: una confusión o solapamiento de jurisdicciones entre el proceso constitucional de amparo y el previo recurso contencioso electoral ante los tribunales ordinarios, y la indeterminación del contenido del derecho fundamental del cual la ley es regulación directa. Pero puede que valga la pena pagarlo. Todo lo cual revela que se ha producido una mutación del artículo 70.2 CE —un cambio de lectura de una norma y del sentido de la misma que no arranca de la reforma constitucional de la disposición escrita sino de su exégesis y desarrollo- que confía la validez de las actas electorales al control de la jurisdicción ordinaria. ${ }^{39}$

Haciendo de los defectos virtudes, con un realismo que es bueno en materia de garantías, incrementar las competencias del Tribunal Constitucional y su función revisora de los conflictos electorales, puede contribuir a preservar la verdad material, la voluntad popular, y a unificar los criterios interpretativos de las normas electorales en cuanto típica ventaja de una jurisdicción concentrada con toda la panoplia de herramientas procesales y la riqueza de medios materiales y personales propia de un Tribunal Constitucional.

${ }^{39}$ Cfr. Jellinek, Georg, Reforma y mutación de la Constitución, Madrid, Centro de Estudios Constitucionales, 1991, original en alemán de 1906, estudio preliminar de Pablo Lucas Verdú. 